\title{
Intraseasonal Modulation of the Surface Cooling in the Gulf of Guinea
}

\author{
JULIEN JOUANNO \\ Departamento de Oceanografía Física, CICESE, Ensenada, Baja California, Mexico \\ FRÉDÉRIC MARIN \\ IRD, LEGOS, Nouméa, New Caledonia, and UPS (OMP-PCA), LEGOS, Université de Toulouse, Toulouse, France \\ YVES DU PENHOAT \\ IRD, CRHOB, Cotonou, Bénin, and UPS (OMP-PCA), LEGOS, Université de Toulouse, Toulouse, France \\ JEAN-MARC MOLINES \\ MEOM, LEGI-CNRS, Grenoble, France
}

(Manuscript received 20 March 2012, in final form 27 October 2012)

\begin{abstract}
A regional numerical model of the tropical Atlantic Ocean and observations are analyzed to investigate the intraseasonal fluctuations of the sea surface temperature at the equator in the Gulf of Guinea. Results indicate that the seasonal cooling in this region is significantly shaped by short-duration cooling events caused by windforced equatorial waves: mixed Rossby-gravity waves within the 12-20-day period band, inertia-gravity waves with periods below 11 days, and equatorially trapped Kelvin waves with periods between 25 and 40 days. In these different ranges of frequencies, it is shown that the wave-induced horizontal oscillations of the northern front of the mean cold tongue dominate the variations of mixed layer temperature near the equator. But the model mixed layer heat budget also shows that the equatorial waves make a significant contribution to the mixed layer heat budget through modulation of the turbulent cooling, especially above the core of the Equatorial Undercurrent (EUC). The turbulent cooling variability is found to be mainly controlled by the intraseasonal modulation of the vertical shear in the upper ocean. This mechanism is maximum during periods of seasonal cooling, especially in boreal summer, when the surface South Equatorial Current is strongest and between $2^{\circ} \mathrm{S}$ and the equator, where the presence of the EUC provides a background vertical shear in the upper ocean. It applies for the three types of intraseasonal waves. Inertia-gravity waves also modulate the turbulent heat flux at the equator through vertical displacement of the core of the EUC in response to equatorial divergence and convergence.
\end{abstract}

\section{Introduction}

The most characteristic feature of the tropical Atlantic is the seasonal appearance of a tongue of cool sea surface temperature (SST) along and south of the equator (e.g., Carton and Zhou 1997). This signal is strongest in the Gulf of Guinea, where the thermocline is shallow (Picaut 1983) and the vertical mixing is strong (Peter et al. 2006; Jouanno et al. 2011a). There, SST drops from more

Corresponding author address: Julien Jouanno, Departamento de Oceanografía Física, CICESE, Ensenada, Baja California, Mexico.

E-mail: jouanno@cicese.mx than $28^{\circ}$ to $23^{\circ} \mathrm{C}$ between April and August. As a result of this seasonal cooling, a sharp meridional temperature gradient exists close to the equator (e.g., Marin et al. 2009). It has been shown that this meridional gradient exerts a significant influence on the African monsoon, intensifying the southerly winds in the Gulf of Guinea, and pushing the continental rain band to the north (Okumura and Xie 2004; Caniaux et al. 2011).

Besides this dominant seasonal cycle, strong intraseasonal modulation of the SSTs is observed in the equatorial Atlantic. In the Gulf of Guinea, defined here as the region from $5^{\circ} \mathrm{W}$ to the African Coast, temperature fluctuations occur predominantly in the 10-20-day band as first pointed out by Houghton and Colin (1987). 
This SST signal at the equator is commonly explained by the meridional displacement of the northern front of the mean cold tongue by anomalous cross-equatorial currents (Houghton and Colin 1987; Athié and Marin 2008; Marin et al. 2009; de Coëtlogon et al. 2010). This variability is mainly observed from May to August, when the front is well defined.

Contrary to the western tropical Atlantic where winds at the equator are zonal, the Gulf of Guinea is also under influence of meridional southerly monsoon winds (Picaut 1984). These winds fluctuate with a period close to 15 days (Krishnamurti and Krishnamurti 1980). Houghton and Colin (1987) found a high coherence between the meridional ocean velocity and the meridional wind stress at $0^{\circ}, 4^{\circ} \mathrm{W}$ in the 10-20-day band, with the meridional wind stress leading the meridional velocity by a few days. Marin et al. (2009) also concluded that the undulations of the thermal front in the Gulf of Guinea were in phase with wind intensification. From a regression analysis of satellite observations, de Coëtlogon et al. (2010) found a 5-day lag between the wind peaks and cold SST anomalies in the 10-20-day band of frequency. This variability contrasts with the western part of the basin where the intraseasonal modulation of the SST is dominated by 25-40-day fluctuations associated with the tropical instability waves (TIWs), which are triggered by the instabilities of the tropical oceanic currents (e.g., von Schuckmann et al. 2008; Perez et al. 2012).

Besides the observational evidence that the 15-day variability of the meridional surface velocities is forced by the wind, the dynamical response of the upper ocean to 15-day wind fluctuations is still not fully understood. As mentioned by Picaut (1984), there is a discrepancy between the zonal wavelengths of the atmospheric forcing $(\sim 4000 \mathrm{~km})$ and of the oceanic response $(\sim 2000 \mathrm{~km})$. Several studies have tried to associate the observed 15-day variability with equatorial waves. From the frequency, meridional length scale, and asymmetry about the equator of the observed thermocline displacements, Houghton and Colin (1987) suggested that the meridional velocity fluctuations were the signature of a second baroclinic mode Rossby-gravity wave locally forced by the wind.

An important issue is whether these 15-day fluctuations make a significant contribution to the surface cooling or whether they merely displace the meridional front of SST. Marin et al. (2009) suggest that intraseasonal winds in the Gulf of Guinea are a major contributor to the seasonal SST cooling south of the equator. They show that quick and intense wind-induced cooling events produce persistent cold SST anomalies, leading to a stepwise evolution of the SST in response to the wind events. They suggest that this is due to locally intensified mixing at the mixed layer base in response to intensified southeasterlies. Modeling results of de Coëtlogon et al. (2010) confirm that subsurface processes are important contributors to the net intraseasonal cooling. Nevertheless, none of these studies could distinguish the respective roles of horizontal diffusion, vertical advection, and vertical mixing induced by wind or sheared currents.

Recent observational and model studies have shown that vertical mixing plays a key role for seasonal cooling at the equator (Peter et al. 2006; Wade et al. 2011a; Jouanno et al. 2011b). Although Caniaux et al. (2011) explain the seasonal cycle and spatial distribution of the Atlantic cold tongue with a simple model of the Ekman pumping at the equator, numerical results from Jouanno et al. (2011a) suggest that the seasonal cooling and the southern extension of the summer cold tongue are mainly driven by the acceleration of the northern and southern branches of the South Equatorial Current (SEC), through the modulation of vertical shear in subsurface.

At intraseasonal scale, there are pieces of evidence that TIWs in the Pacific can enhance mixing and cooling by the shear they induce in subsurface. This has been first shown in a numerical study (Menkes et al. 2006) and then supported by the analysis of a Lagrangian float (Lien et al. 2008) and from profiling measurements of turbulence dissipation rate (Moum et al. 2009). In the Gulf of Guinea, the 15-day perturbations, which dominate the intraseasonal variability of the surface currents, as well as other regimes of intraseasonal variability could modulate the vertical and horizontal structure of the currents in such a way they could induce intraseasonal fluctuations of the turbulent heat flux. To our knowledge, this has never been investigated.

The purpose of the present paper is to examine the intraseasonal variability of the surface cooling in the Gulf of Guinea. We will investigate the processes responsible for the intraseasonal modulation and spatial characteristics of the cooling. The paper is organized as follows. A description of model and data is given is section 2. Section 3 discusses the processes responsible for intraseasonal cooling in the Gulf of Guinea. A special focus is given to summer 2006 to illustrate some findings. We chose this particular year because some aspects of its variability have already been described in detail in Marin et al. (2009), but the results are generalized to the last decade (2001-09) in the subsequent section. Section 4 investigates the mechanisms whereby the most energetic waves in the Gulf of Guinea impact the surface cooling. Section 5 provides a discussion and summary of the results. 


\section{Model and data}

The simulation used in this study is similar to the one described and analyzed in Jouanno et al. (2011a,b), apart from an increased vertical resolution and the use of European Centre for Medium-Range Weather Forecasts (ECMWF) Interim Re-Analysis (ERA-Interim) forcing (see Dee et al. 2011 for a validation of ERAInterim products in the tropical Atlantic). The numerical code is that of the ocean general circulation model Nucleus for European Modelling of the Ocean (NEMO; Madec 2008). It solves the three-dimensional primitive equations in spherical coordinates discretized on a $\mathrm{C}$ grid and fixed vertical levels. The model design is a tropical Atlantic regional configuration at $1 / 4^{\circ}$ horizontal resolution. There are 75 levels in the vertical (with 12 levels in the upper $20 \mathrm{~m}$ and 24 levels in the upper $100 \mathrm{~m}$ ). The model is forced at its boundaries $\left(20^{\circ} \mathrm{S}-20^{\circ} \mathrm{N}\right.$ and $\left.60^{\circ} \mathrm{W}-15^{\circ} \mathrm{E}\right)$ using radiative open boundary condition, with outputs from the global interannual experiment ORCA025-MJM95 developed by the DRAKKAR team (Barnier et al. 2006). The vertical turbulent mixing is parameterized using a level-1.5 turbulence closure scheme, with a prognostic equation for turbulence kinetic energy (TKE) and a diagnostic equation for length scale (Blanke and Delecluse 1993). The atmospheric fluxes of momentum, heat and freshwater are provided by bulk formulae (Large and Yeager 2004) and ERA-Interim reanalysis from ECMWF (3-h fields of wind, atmospheric temperature and humidity; daily fields of long, short wave radiation and precipitation). The short wave radiation forcing is modulated by a theoretical diurnal cycle. The model is initialized on 1 January 1999 with temperature and salinity outputs from the ORCA025-MJM95 global experiment at the same date, and then integrated over the period 1999-2009. Daily averages from 2001 to 2009 are analyzed. We refer the reader to Jouanno et al. (2011a,b) for further details on the parameterization and some elements of validation, including comparisons with in situ observations of temperature, currents, and vertical shear as well as comparisons with satellite observations of SST and chlorophyll concentrations. The model SST in the cold tongue is warmer than in observations (Fig. 1), but the $1^{\circ} \mathrm{C}$ bias in the previous configuration has been reduced to $0.5^{\circ} \mathrm{C}$ in the present simulation. Several factors may contribute to this improvement. First, the increased vertical resolution allows a better simulation of the vertical shear of the current and associated vertical mixing. Second, the diurnal modulation of the shortwave radiation forces nighttime convection, which is expected to have an impact on the mixed layer heat budget in the region (Wade et al. 2011b). Third, the use of ERA-Interim
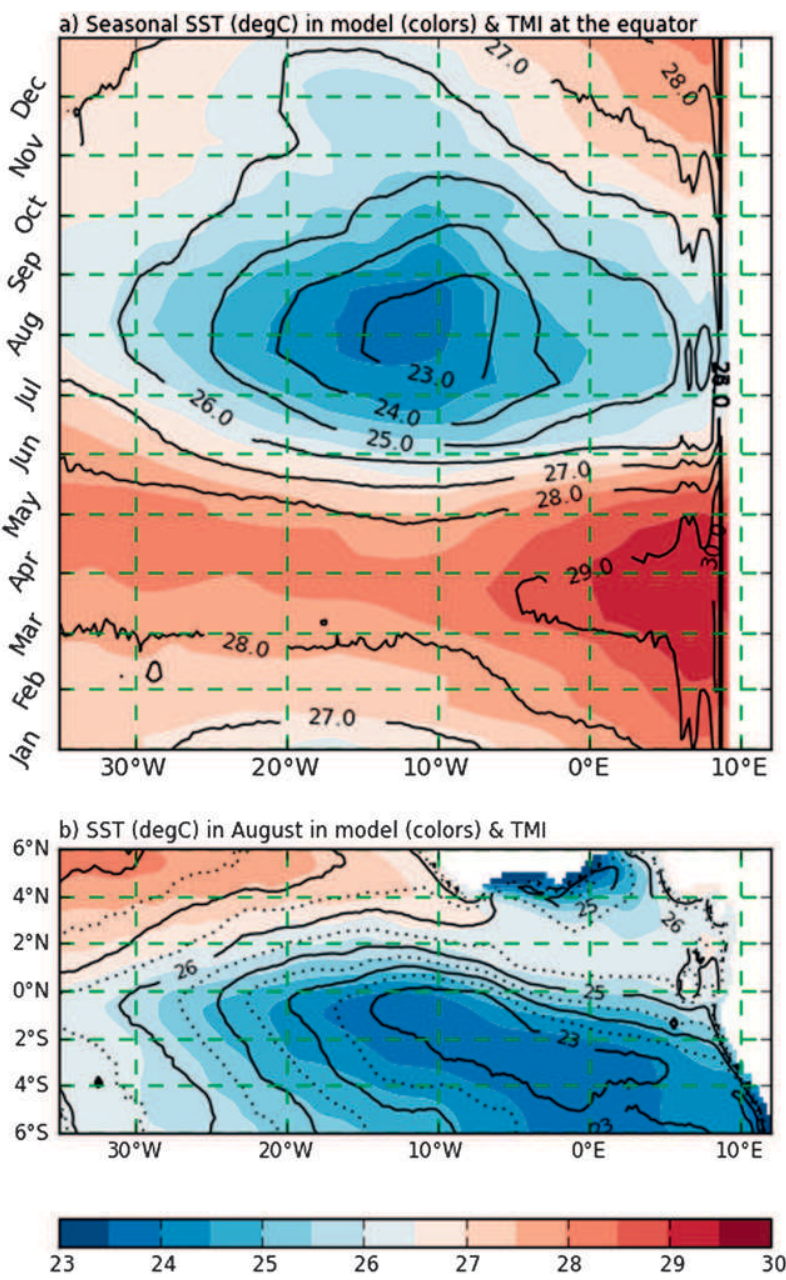

FIG. 1. (a) Seasonal cycle of equatorial SST $\left({ }^{\circ} \mathrm{C}\right)$ for the period 2001-09, computed with model (colors) and TMI observations (TRMM Microwave Imager) [see Kummerow et al. 1998]. Data were averaged between $1^{\circ} \mathrm{S}$ and the equator. Interval between contours is $1^{\circ} \mathrm{C}$. (b) Horizontal distribution of 2001-09 climatological SST in August for the model (colors) and satellite TMI observations (contours). Interval between contours is $0.5^{\circ} \mathrm{C}$ (solid lines for integer values, dotted lines otherwise).

forcing, with higher temporal resolution compared to the 40-yr ECMWF Re-Analysis (ERA-40) forcing used in Jouanno et al. (2011a,b), may also contribute to improve the solution of the model.

Following Menkes et al. (2006) and Peter et al. (2006), the mixed layer heat budget has been computed online to quantify precisely the contributions of atmospheric forcing, horizontal advection, vertical advection, vertical mixing, horizontal diffusion, and entrainment to the mixed layer temperature tendency. This diagnostic is described in detail in Jouanno et al. (2011b). In the present study, we will focus on the term of mixed layer temperature tendency due to turbulent heat flux at the mixed layer base. This term is computed online as 

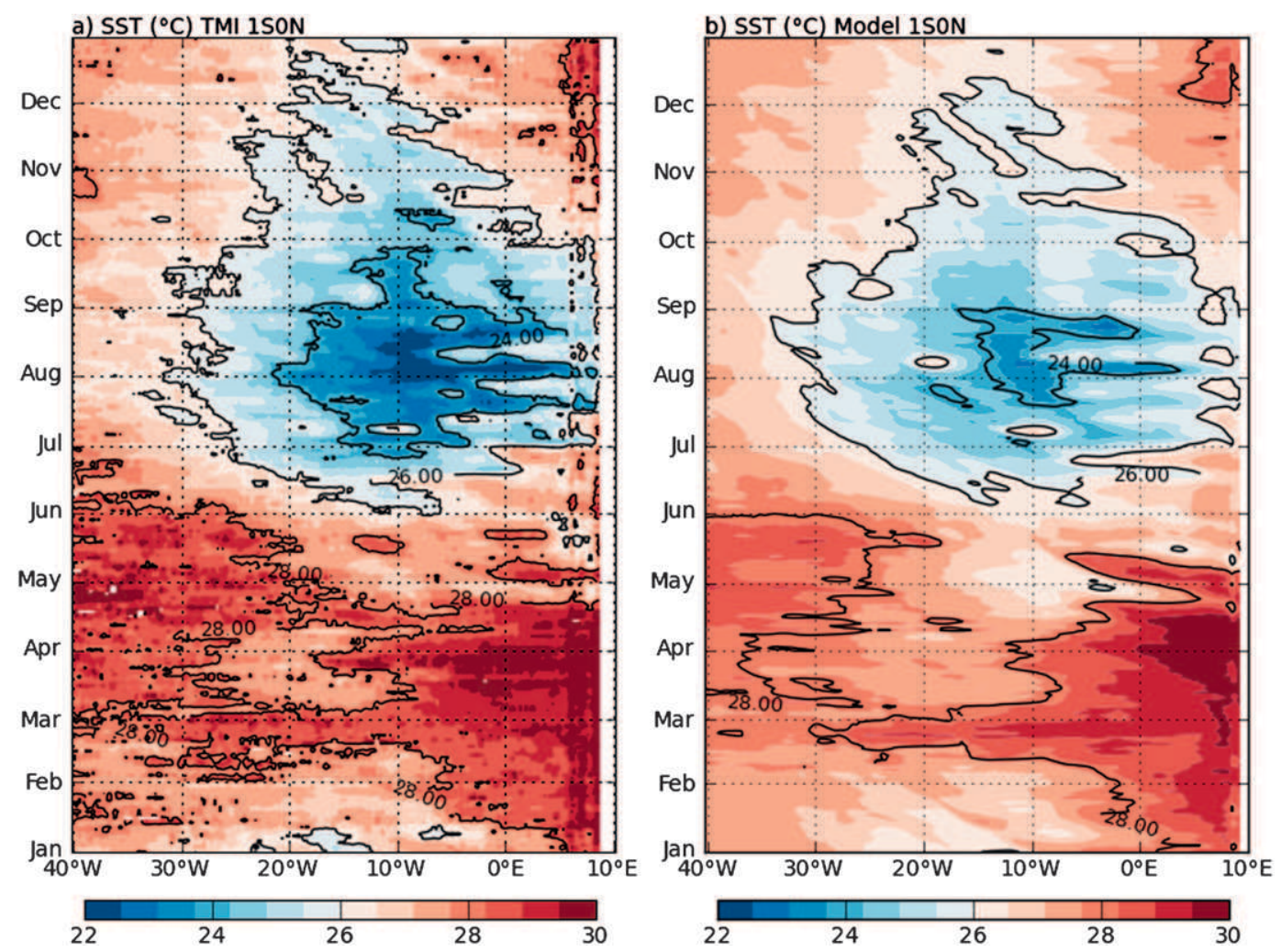

FIG. 2. Longitude-time diagrams of sea surface temperature $\left({ }^{\circ} \mathrm{C}\right)$ at the equator from (a) satellite and (b) model during year 2006. The daily data were meridionally averaged between $1^{\circ} \mathrm{S}$ and the equator. Contours represent the $24^{\circ}, 26^{\circ}$, and $28^{\circ} \mathrm{C}$ isotherms.

$(-1 / h)\left(K_{z} \partial_{z} T\right)_{z=-h}$, where $h$ is the mixed layer depth, $K_{z}$ is the vertical diffusion coefficient, and $T$ is the model potential temperature. The mixed layer depth is computed as the depth where density increase compared to density at $10 \mathrm{~m}$ equals $0.03 \mathrm{~kg} \mathrm{~m}^{-3}$. Threedimensional daily turbulent heat fluxes have also been computed online at each model grid point and at each time-step, following Jouanno et al. (2011a). The current shear is quantified by the squared vertical gradient of horizontal velocity, $S^{2}=S_{u}^{2}+S_{v}^{2}=u_{z}^{2}+v_{z}^{2}$; where $u$ and $v$ represent the zonal and meridional components of the velocity and subscript $\mathrm{z}$ represents vertical gradient.

In addition to this reference experiment (REF), an experiment forced with monthly winds (all other forcing fields being kept at their original temporal resolution) has been carried out. In this experiment, which will be referred to as MONTHLY in the following sections, the wind forcing is built as the monthly average of the ERAInterim winds used to force REF experiment.

Numerical results are compared with satellite SST from TMI [Tropical Rainfall Measuring Mission (TRMM) Microwave Imager, Kummerow et al. (1998)]. In situ temperature data at $0^{\circ}, 0^{\circ}$, with a vertical resolution of $20 \mathrm{~m}$ between the surface and 140-m depth, are from the Prediction and Research Moored Array in the Tropical Atlantic (PIRATA) buoy (Bourlès et al. 2008). Model wind stress is compared against Quick Scatterometer (QuikSCAT) wind stress (Bentamy et al. 2002) and PIRATA observations. Daily averages from 2001 to 2009 are used for SST and in situ data.

\section{Intraseasonal modulation of the SST in the Gulf of Guinea}

The temporal evolution during 2006 of the observed equatorial SST (Fig. 2a) illustrates that besides the dominant seasonal cycle, strong SST fluctuations occur in the Gulf of Guinea (east of $5^{\circ} \mathrm{W}$ ) from May to September. These fluctuations have large zonal scales (between $10^{\circ} \mathrm{W}$ and $5^{\circ} \mathrm{E}$ ), no apparent zonal propagation, and their period is close to 15 days. The variance-conserving spectrum of $\partial \mathrm{SST} / \partial t$, computed with in situ data from the PIRATA buoy at $0^{\circ}, 0^{\circ}$ (Fig. 3), confirms that processes with periods between 12 and 20 days dominate the SST variability in the region. The two peaks at 14 and 16 days have the highest energy and occur with 


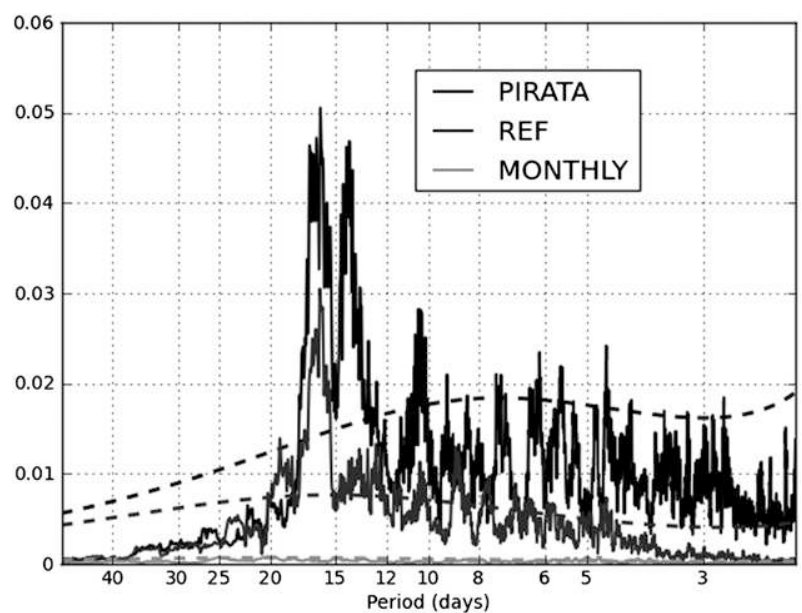

FIG. 3. Multitaper variance-conserving power spectra of PIRATA (black), REF experiment (gray), and MONTHLY experiment (light gray) sea surface temperature tendencies $(\partial \mathrm{SST} / \partial t)$ at $0^{\circ}, 0^{\circ}\left({ }^{\circ} \mathrm{C}^{2}\right.$ day $^{-2}$ day $\left.^{-1}\right)$, using $K=7$ windows. Temperature tendencies were computed using daily data from January 2001 to December 2009. Dotted lines represent the corresponding $90 \%$ confidence limit based on the theoretical spectra of an AR(2) process with variances equal to that of the analyzed signals. The number of degrees of freedom for the $90 \%$ level calculation is estimated as $2 K-1$.

similar amplitude. Besides this dominant variability strong spectral power also occurs at higher frequencies, as shown by the multiple peaks occurring at periods below 11 days. The spectra of ERA-Interim wind stress at the same location also presents two peaks at 14 and 16 days, and significant energy at higher frequencies as well (Fig. 4b). This indicates a close relationship between the surface conditions and the wind forcing.

In the Gulf of Guinea, the phase and zonal extent of the intraseasonal fluctuations of the simulated SST (Fig. 2b) compare reasonably well with satellite observations (Fig. 2a). The spectral analysis (Fig. 3) also shows a reasonable agreement between model and observations in terms of energy distribution among the different frequencies. This suggests that the intraseasonal variability of the SSTs can be investigated from our simulation. The main difference between model and observations concerns the amplitude of the fluctuations in the Gulf of Guinea, which is lower in the model (see Fig. 2), and the amplitude of the 14-day peak, which is much lower than the 16-day in the model but not in the observations. Moreover, the overall energy of the model spectrum is lower than the energy of the observed spectrum (Fig. 3). There are two possible explanations for this discrepancy. First, the simulated seasonal cold tongue is not as cold as the observed cold tongue (see Fig. 1). As seen in Marin et al. (2009), the cold tongue in the Gulf of Guinea is limited by a sharp front that oscillates
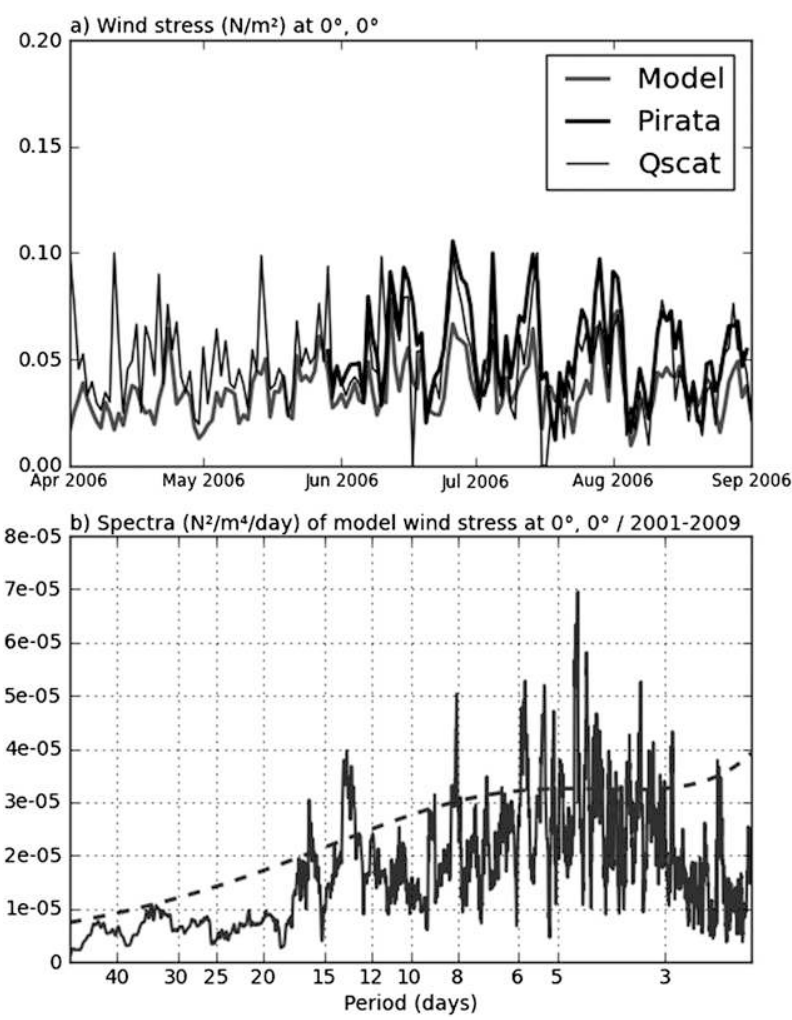

FIG. 4. (a) Wind stress magnitude $\left(\mathrm{N} \mathrm{m}^{-2}\right)$ at $0^{\circ}, 0^{\circ}$ from model (gray line), PIRATA buoy (black thick line), and QuikSCAT (thin black line). Data are shown between April and September 2006. (b) Multitaper variance-conserving power spectra of model wind stress at $0^{\circ}, 0^{\circ}\left(\mathrm{N}^{2} \mathrm{~m}^{-4}\right.$ day $\left.^{-1}\right)$, using $K=7$ windows as in Fig. 3 .

between $2^{\circ} \mathrm{S}$ and $2^{\circ} \mathrm{N}$. A warm bias in the simulated cold tongue weakens the meridional gradient of temperature at the location of the front, which in turn weakens the amplitude of the simulated SST anomalies caused by the oscillations of the front. Second, the comparison between model wind stress and wind stress derived from PIRATA observations at $0^{\circ}, 0^{\circ}$ or QuickSCAT data at the same location indicates that the intraseasonal variability of ERA-Interim winds is in phase with observations but that its amplitude is too low (Fig. 4a). This was noted in the Atlantic equatorial basin by Praveen Kumar et al. (2013) who showed a good agreement between ERA-Interim and PIRATA wind stress, although the variability of ERA-Interim wind stress in the 10-90-day band was found to be systematically weaker. This bias is expected to reduce the amplitude of the wind-forced upper-ocean variability. In terms of distribution of the zonal and meridional wind stress variability into different intraseasonal frequency bands, Yu et al. (2011) have shown a good agreement between ERA-Interim and QuikSCAT. Note that the good phasing between the observed and ERA-Interim 
wind bursts (Fig. 4a) explains the good phasing between model and observed SST signals (Figs. 2a,b).

A latitude-time diagram of observed SST at $0^{\circ}$ is shown in Fig. 5a from April to September 2006. A zonal average over the $4^{\circ} \mathrm{W}-4^{\circ} \mathrm{E}$ longitude range has been applied to SST. We have chosen this range of longitude since 1) the longitude-time diagram in Fig. 2 indicates that the biweekly fluctuations are zonally coherent over this area during summer, and 2) it allows a direct comparison with observations in Marin et al. (2009). Once again there is a good agreement between the variability of observed and model SST (Figs. 5a,b). The mixed layer temperature tendency is shown in Fig. 5c. It illustrates that the strongest SST variability occurs between $2^{\circ} \mathrm{S}$ and $2^{\circ} \mathrm{N}$. The successive positive and negative anomalies centered at the equator are partly the signature of the meridional oscillations of the SST front (Fig. 5b). This is highlighted by the term of mixed layer temperature tendency due to meridional advection (Fig. $5 \mathrm{~g}$ ). We remark in Figs. 5a and $5 \mathrm{~b}$ that south of the equator (between $4^{\circ} \mathrm{S}$ and the equator), net cooling generally occurs simultaneously to the oscillations of the front, leading to a stepwise evolution of the seasonal cooling, as already observed by Marin et al. (2009) for years 2005 and 2006. This net cooling south of the equator is not explained by the temperature tendency owing to meridional advection (Fig. $5 \mathrm{~g}$ ) and is due to increased turbulent heat flux at the mixed layer base (Fig. $5 \mathrm{~d}$ ). In the equatorial region, the cooling induced by vertical mixing is of same order than that induced by meridional advection (Figs. $5 \mathrm{~d}, \mathrm{~g})$. The impact of the vertical advection at the mixed layer base (Fig. 5h) is small compared to that of the turbulent heat fluxes. Moreover, the air-sea fluxes (Fig. 5e) mostly warm the region of cooled waters in response to subsurface cooling. The term of zonal advection mainly contributes to a warming of the equatorial region (Fig. 5f). The terms of lateral diffusion are negligible (not shown). The term of entrainment, which represents the variations of mixed layer temperature due to deepening or raising of the mixed layer depth, is also negligible compared to the other terms (not shown). These characteristics are in agreement with the model mixed layer seasonal heat balance, as described in Jouanno et al. (2011b).

The model mixed layer depth (Fig. 5j) is generally shallow $(\sim 10 \mathrm{~m})$ when the turbulent cooling is strong (Fig. 5d) and when the contribution of the air-sea heat fluxes is positive (Fig. 5e). Conversely, the mixed layer deepens when the vertical mixing is low and when the contribution of air-sea heat fluxes is negative. This is expected since cooling at the surface triggers convective events which deepen the mixed layer (not shown), and vertical mixing tends to erode the base of the mixed

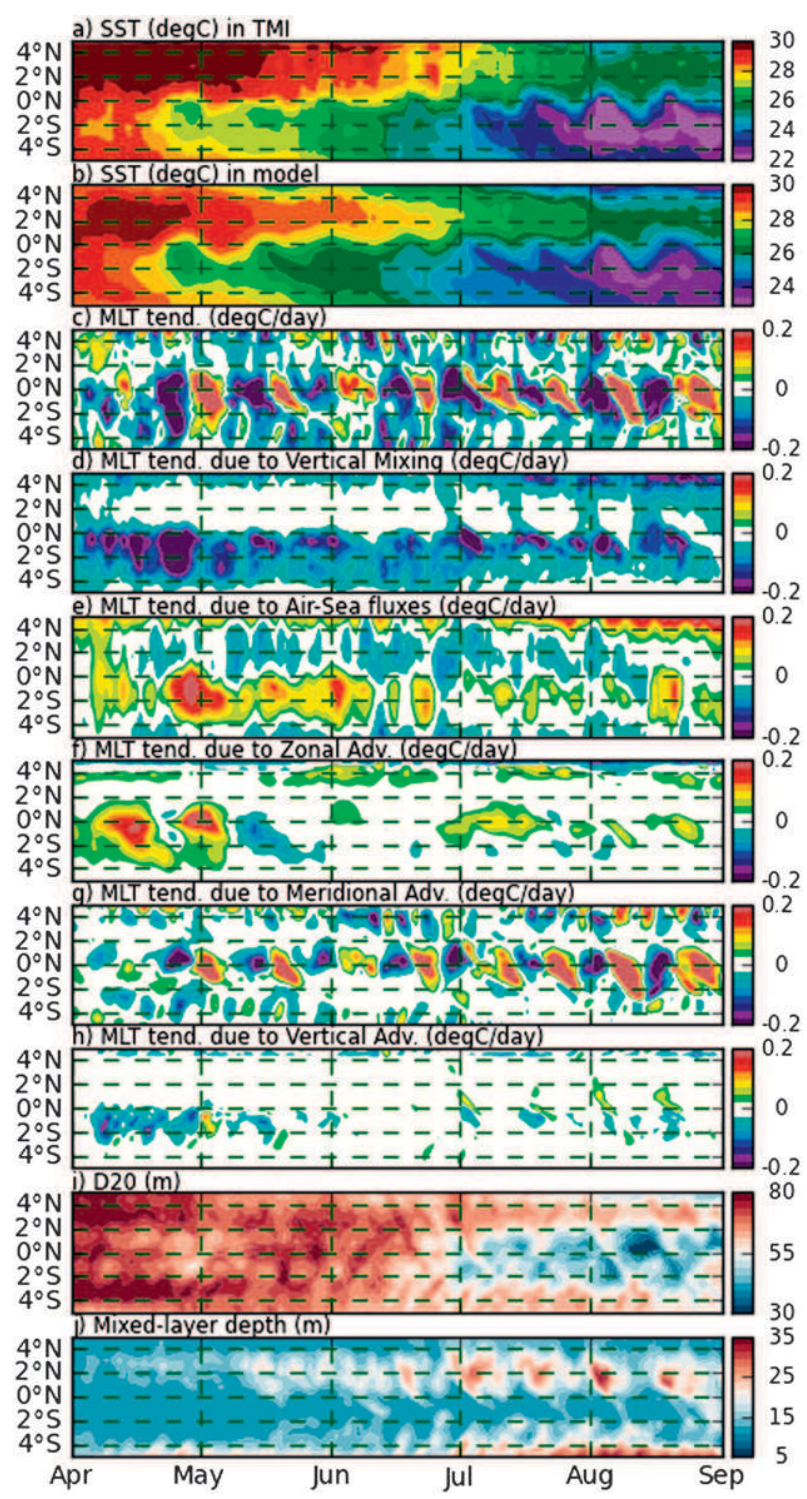

FIG. 5. Latitude-time diagrams during the cooling season in 2006 of (a) TMI SST, (b) model SST, (c) mixed layer temperature tendency, mixed layer temperature tendency due to turbulent heat fluxes at the base of the mixed layer $\left({ }^{\circ} \mathrm{C}\right.$ day $\left.^{-1}\right),(\mathrm{e})$ mixed layer temperature tendency due to air-sea fluxes $\left({ }^{\circ} \mathrm{C}\right.$ day $\left.{ }^{-1}\right)$, (f,g,h) mixed layer temperature tendency due to zonal, meridional and vertical advection at the base of the mixed layer $\left({ }^{\circ} \mathrm{C}\right.$ day $\left.{ }^{-1}\right)$, (i) depth of the $20^{\circ} \mathrm{C}$ isotherm, and (j) mixed layer depth (m). Data are zonally averaged between $4^{\circ} \mathrm{W}$ and $4^{\circ} \mathrm{E}$.

layer. Only results for year 2006 are presented in this section, but we verified that similar conclusions are reached for all years between 2001 and 2009.

The cold tongue starts to form in mid-April (Figs. 5a,b), before the seasonal raising of the thermocline (illustrated in Fig. $5 \mathrm{i}$ by the depth of the $20^{\circ} \mathrm{C}$ isotherm), which occurs in 2006 at the end of June. This is in agreement with Jouanno et al. (2011b) who argued that 


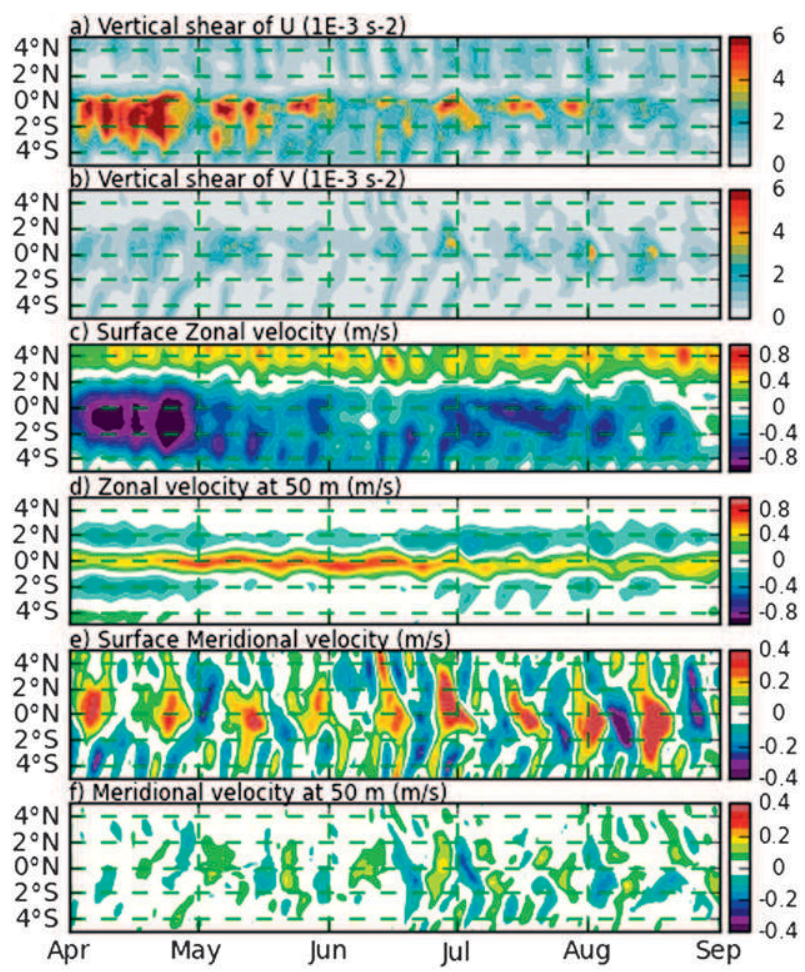

FIG. 6. Latitude-time diagrams during the cooling season in 2006 of (a) maximum value in the upper $50 \mathrm{~m}$ of $S_{u}^{2}$ the vertical shear squared due to zonal velocities $\left(\mathrm{s}^{-2}\right)$, (b) maximum value in the upper $50 \mathrm{~m}$ of $S_{v}^{2}$ the vertical shear squared due to meridional velocities $\left(\mathrm{s}^{-2}\right)$, (c) surface zonal current $\left(\mathrm{m} \mathrm{s}^{-1}\right)$, (d) zonal current at $50 \mathrm{~m}$ depth $\left(\mathrm{m} \mathrm{s}^{-1}\right),(\mathrm{e})$ surface meridional current $\left(\mathrm{m} \mathrm{s}^{-1}\right)$, and (f) meridional current at $50 \mathrm{~m}$ depth $\left(\mathrm{m} \mathrm{s}^{-1}\right)$. Data are zonally averaged between $4^{\circ} \mathrm{W}$ and $4^{\circ} \mathrm{E}$.

the seasonal cooling is primarily driven by vertical mixing due to increased vertical shear above the EUC associated with the westward acceleration of the surface currents. At first order, it appears that such mechanism is also valid at intraseasonal frequencies: comparison between Fig. 5d and Fig. 6a shows a good correspondence between the turbulent heat flux and the squared vertical shear of the zonal currents $S_{u}^{2}$ at intraseasonal time scales. This shear is maximum at and south of the equator, above the core of the eastward-flowing EUC (Fig. 6d), and its variability appears to be modulated by that of the zonal surface flow (Fig. 6c). Note that strong surface currents occur south of the EUC core (from $4^{\circ} \mathrm{S}$ to the equator), causing turbulent cooling off the equator as well. An example is the strong westward flow in April 2006 (Fig. 6c), which significantly increased the turbulent cooling south of $2^{\circ} \mathrm{S}$ (Fig. 5d). Sometimes, the vertical shear of the meridional flow $S_{v}^{2}$ can also be strong right at the equator (e.g., between July and August in Fig. 6b). This is due to energetic fluctuations of the surface meridional currents at periods close to 15 days
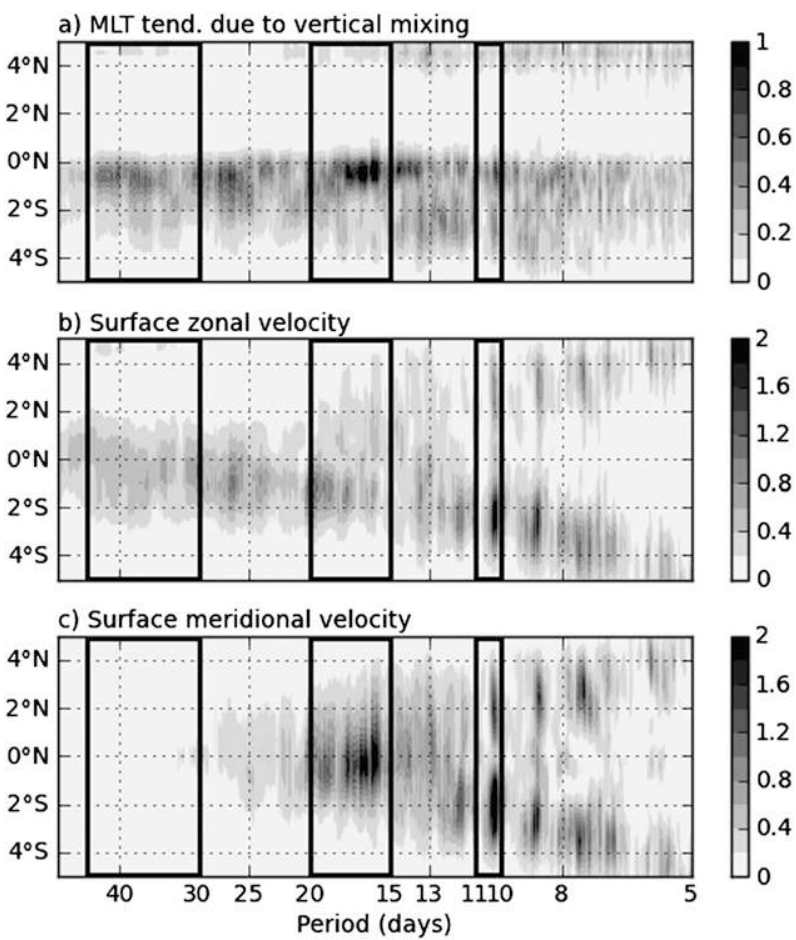

FIG. 7. Variance-conserving multitaper power spectra (7 windows) as a function of latitude of (a) mixed layer temperature tendency due to turbulent heat fluxes $\left(10^{-3 \circ} \mathrm{C}^{2}\right.$ day $\left.^{-2}\right)$, (b) zonal surface velocity $\left(10^{-2} \mathrm{~m}^{2} \mathrm{~s}^{-2}\right)$, and (c) meridional surface velocity $\left(10^{-2} \mathrm{~m}^{2} \mathrm{~s}^{-2}\right)$. Data were zonally averaged between $4^{\circ} \mathrm{W}$ and $4^{\circ} \mathrm{E}$ before spectral analysis. The black boxes delimit the different frequency bands used for the regression analysis in Section 4.

(Fig. 6e), that are not present at $50 \mathrm{~m}$ depth (Fig. 6f). However the variability of the vertical shear of the meridional flow remains of second order when compared to that of the zonal flow.

From the analysis of these latitude-time diagrams, it appears that regimes of variability are different on and off equator. For example fluctuations of the meridional surface velocity are of lower frequency at the equator than south of $2^{\circ} \mathrm{S}$ (Fig. 6e). To get further insight into this point, the spectra of both mixed layer turbulent cooling and surface currents averaged between $4^{\circ} \mathrm{W}$ and $4^{\circ} \mathrm{E}$ are computed as a function of latitude between $5^{\circ} \mathrm{S}$ and $5^{\circ} \mathrm{N}$ (Fig. 7). The variability of the mixed layer turbulent cooling is maximum between $1^{\circ} \mathrm{S}$ and the equator, with maximum energy between 13 and 20 days (Fig. 7a). In this period range, the variability of the meridional surface currents is maximum at the equator (Fig. 7c), while that of the zonal current is maximum at $1^{\circ} \mathrm{S}$ (Fig. $7 \mathrm{~b}$ ). This is compatible with the meridional structure of mixed Rossby-gravity waves, although we would expect from the linear theory equivalent amplitude of the zonal currents north and south of the equator (Weisberg et al. 

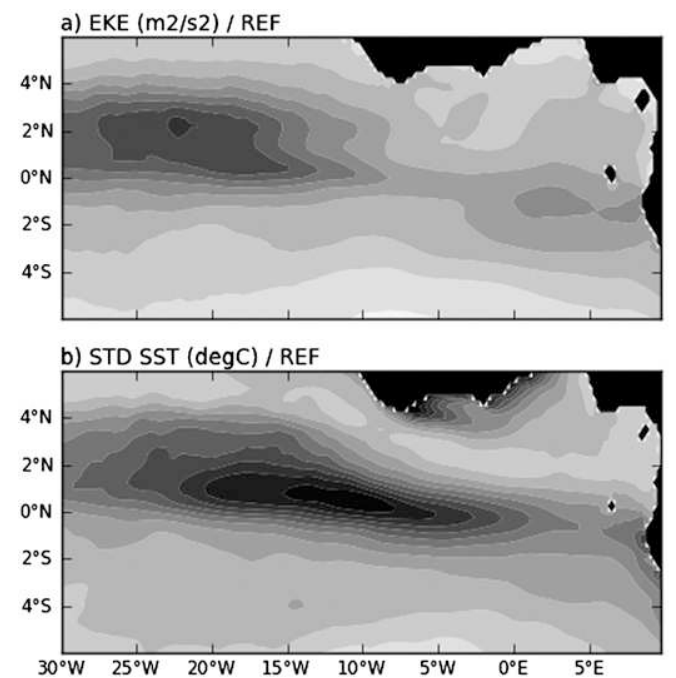

FIG. 8. (a)-(c) Comparison of surface eddy kinetic energy $\left(\mathrm{N}^{2} \mathrm{~m}^{-2}\right)$ and (b)-(d) standard deviation of intraseasonal SST anomalies $\left({ }^{\circ} \mathrm{C}\right)$ in (a),(b) REF and (c),(d) MONTHLY experiments. The computation has been performed using surface currents and SST fluctuations high-pass filtered with a cutoff period of 50 days, over the period 2001-09. Contours intervals are $0.005 \mathrm{~N}^{2} \mathrm{~m}^{-2}$ and $0.05^{\circ} \mathrm{C}$, respectively.
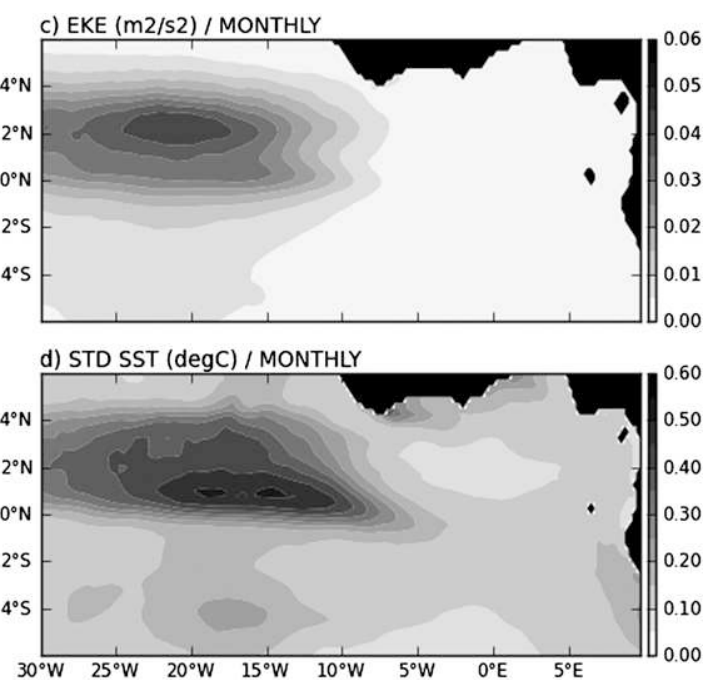

(1) 


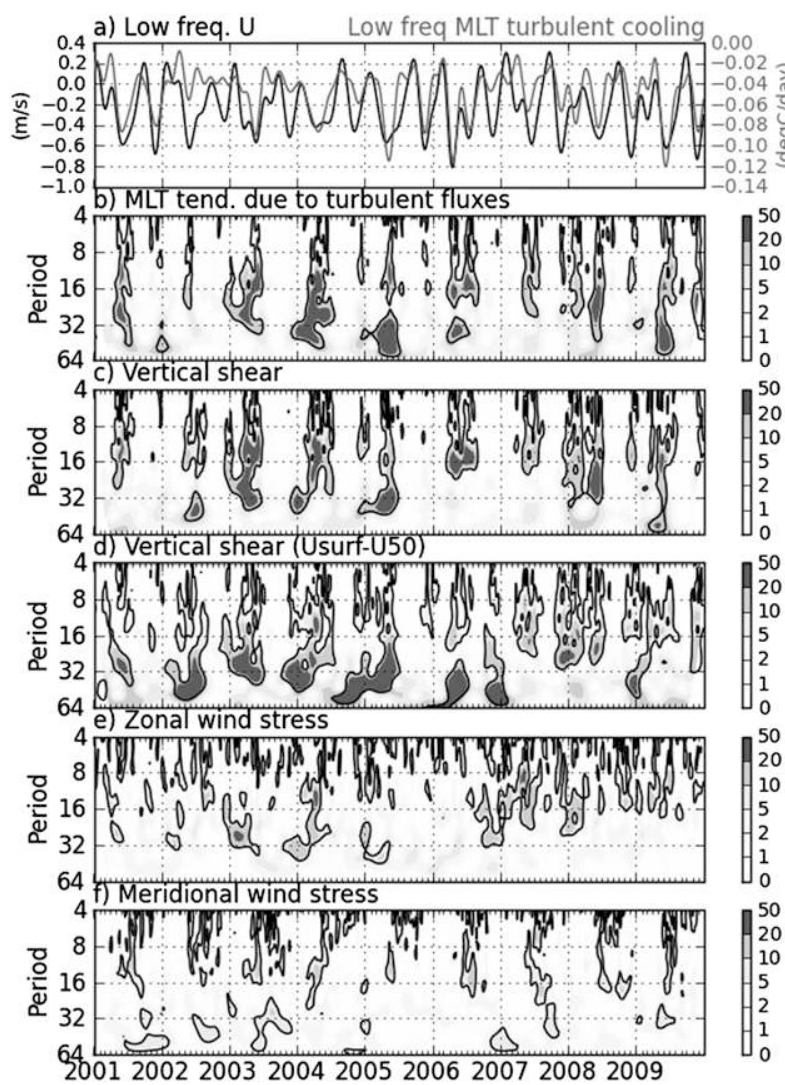

FIG. 9. (a) Time series of low-frequency (70 days cutoff period) surface currents and mixed layer temperature tendency due to turbulent heat fluxes averaged between $4^{\circ} \mathrm{W}-4^{\circ} \mathrm{E}$ and $1^{\circ} \mathrm{S}-1^{\circ} \mathrm{N}$. (b) Wavelet power spectrum of the mixed layer temperature tendency due to turbulent heat fluxes, (c) maximum value of $S^{2}$ in the upper $50 \mathrm{~m}$, (d) $S^{2}$ computed from the vertical gradient between the model surface current and a constant velocity of $0.5 \mathrm{~m} \mathrm{~s}^{-1}$ at $50-\mathrm{m}$ depth, (e) zonal wind stress, and (f) meridional wind stress. The power spectra are normalized by $\sigma^{2}$ the variance of the corresponding signals: $9.4 \times 10^{-4}{ }^{\circ} \mathrm{C}^{2} \mathrm{day}^{-2}, 3.6 \times 10^{-7} \mathrm{~s}^{-4}, 4.7 \times$ $10^{-9} \mathrm{~s}^{-4}, 9.3 \times 10^{-5} \mathrm{~N}^{2} \mathrm{~m}^{-4}$, and $8.9 \times 10^{-5} \mathrm{~N}^{2} \mathrm{~m}^{-4}$ respectively. Data were averaged between $4^{\circ} \mathrm{W}-4^{\circ} \mathrm{E}$, and $1^{\circ} \mathrm{S}-1^{\circ} \mathrm{N}$ before wavelet analysis. The thick contour encloses regions of greater than $90 \%$ confidence for an AR(2) process. Vertical dashed lines indicate 1 Jan of each year.

SST east of $5^{\circ} \mathrm{W}$ are significant in REF experiment but are almost null in MONTHLY experiment. This suggests that most of the intraseasonal variability east of $5^{\circ} \mathrm{W}$ is wind-driven. Note that a similar experiment was conducted in Athié et al. (2009) and gave equivalent conclusions.

A wavelet analysis shows strong seasonal modulation of the intraseasonal variability of mixed layer turbulent cooling (Fig. 9b). This seasonal variability generally peaks during spring-summer and is strongly related to the seasonal variability of $S^{2}$ (Fig. 9c). The meridional section at $0^{\circ}$ shows that the mean turbulent heat flux during May-August peaks at $60 \mathrm{~W} \mathrm{~m}^{-2}$ between $2^{\circ} \mathrm{S}$ and the equator and between 10 and $20 \mathrm{~m}$ depth, centered on the base of the mixed layer (Fig. 10a). This value is in agreement with observations of diapycnal heat fluxes within the equatorial region of the Gulf of Guinea, as estimated from turbulent dissipation rates (Hummels et al. 2013). The standard deviation during May-August of model turbulent heat fluxes has been computed in three different frequency bands at $0^{\circ} \mathrm{E}$, reaching $25 \mathrm{~W} \mathrm{~m}^{-2}$ in the 13-20-day band, $30 \mathrm{~W} \mathrm{~m}^{-2}$ in the 2-11-day band and $20 \mathrm{~W} \mathrm{~m}^{-2}$ in the 25-40-day band (Figs. 10c,d).

Interestingly, the seasonal modulation of the intraseasonal surface currents (Fig. 11) does not fully explain that of the turbulent cooling or that of $S^{2}$ (Figs. 9b,c), suggesting that the intensity of both is not completely related to the energy of the equatorial waves. Instead, the comparison between Fig. 9b and Fig. 9a indicates that the intraseasonal variability of $S^{2}$ and turbulent cooling is strong when the seasonal surface current (namely the SEC) is westward and strong, with a slight preference for the boreal spring maximum in SEC intensity. Note that during these periods, the seasonal turbulent cooling is also strong (gray line in Fig. 9a; see also Jouanno et al. 2011a,b). So there is a clear link between the dynamical background conditions and the impact of the waves on the vertical mixing.

A hypothesis to explain this link lies on the dependence of the turbulent cooling on the square value of the vertical shear (and not simply on the vertical shear). The effect of this nonlinearity can be illustrated with the following calculation. Consider a constant zonal velocity of $0.5 \mathrm{~m} \mathrm{~s}^{-1}$ at $50-\mathrm{m}$ depth, which represents a stationary EUC and consider a surface-trapped wave that modulates the zonal surface current with a range of $\pm 0.2 \mathrm{~m} \mathrm{~s}^{-1}$. If the mean surface current is zero, the background shear $S_{0}^{2}$ is equal to $1 \times 10^{-4} \mathrm{~s}^{-2}$, and $\left\langle S^{2}\right\rangle$ the amplitude of the variations of $S^{2}$ induced by the wave is equal to $1.6 \times 10^{-4} \mathrm{~s}^{-2}$. But if the mean surface current velocity is $-0.6 \mathrm{~m} \mathrm{~s}^{-1}$, then $S_{0}^{2}$ is equal to $4.8 \times$ $10^{-4} \mathrm{~s}^{-2}$ and $\left\langle S^{2}\right\rangle$ is equal to $3.5 \times 10^{-4} \mathrm{~s}^{-2}$. We remark that 1) the difference of $\left\langle S^{2}\right\rangle$ between the two cases is significant compared to values of $S_{0}^{2}$ and 2) this difference is of same order than the difference of $S_{0}^{2}$ induced by change in background conditions. So the variations of $S^{2}$ induced by a wave are substantially different depending on the background surface flow conditions. In particular, this shows that the impact of the wave is enhanced when the SEC is strong.

To verify the importance of this nonlinear effect, we performed a wavelet analysis of $S^{2}$ computed from the vertical shear between the model zonal surface current (averaged between $4^{\circ} \mathrm{W}-4^{\circ} \mathrm{E}$ and $1^{\circ} \mathrm{S}-1^{\circ} \mathrm{N}$ ) and a constant 


\section{a) Mean Qzdf}

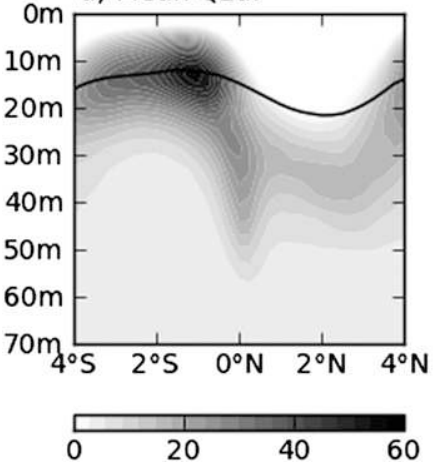

b) STD Qzdf / 13-20-d

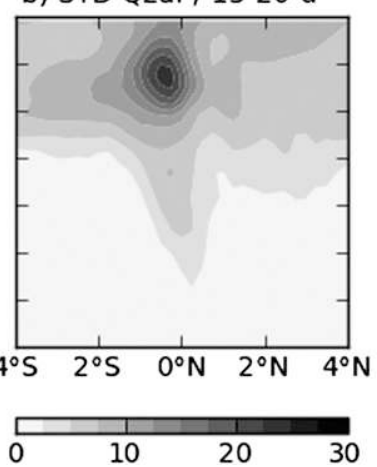

c) STD Qzdf / 2-11-d

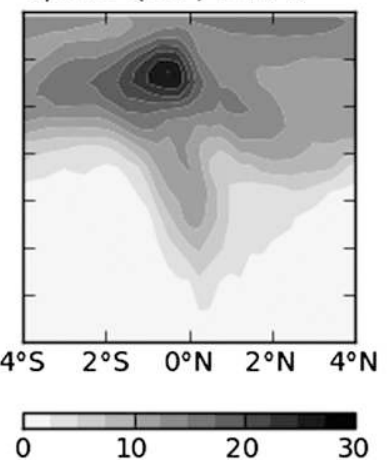

d) STD Qzdf / 25-40-d

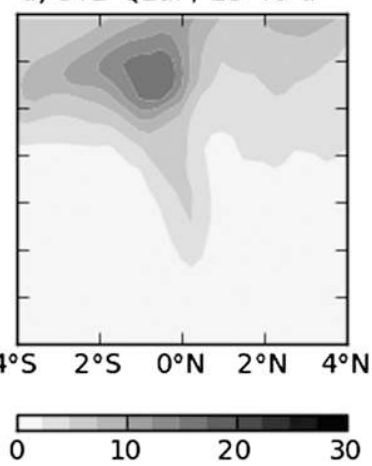

FIG. 10. (a) Meridional sections at $0^{\circ} \mathrm{E}$ of mean turbulent heat flux $\left(\mathrm{W} \mathrm{m}^{-2}\right)$ during May-August and standard deviation $\left(\mathrm{W} \mathrm{m}^{-2}\right)$ of turbulent heat flux bandpass filtered in the (b) 13-20-day, (c) 2-11-day, and (d) 25-40-day bands during this same period. The black line in (a) indicates the base of the mixed layer during May-August. Daily turbulent heat fluxes have been computed online, following Jouanno et al. (2011a).

speed of $0.5 \mathrm{~m} \mathrm{~s}^{-1}$ at $50-\mathrm{m}$ depth (Fig. 9d). The variability of this reconstructed $S^{2}$ is in good agreement with the variability of the maximum value of $\mathrm{S}^{2}$ in the upper $50 \mathrm{~m}$ (Fig. 9c), illustrating that it is the modulation of the shear by the surface current that is primarily controlling the vertical mixing.

\section{Diagnosis of wave-driven mixing}

In this section, a linear regression analysis is performed to get further insight into the spatial structure of some of the waves identified in the previous section, their forcing, and the mechanisms whereby they act on the mixed layer temperature. Regression coefficients at different lags are computed separately on three indices. These indices are defined in such a way to isolate mixed Rossby-gravity waves in the 15-20-day band, inertiagravity waves in the 10-11-day band, and Kelvin waves in the 30-45-day band. These ranges of frequency and these waves are representative of the three main dynamical regimes highlighted in the previous section. They are intentionally narrow in order to isolate only one peak of variability for each regime. Bandpass time filtering is performed with a Lanczos filter. The 15-20day index is defined as the time-filtered surface meridional velocity, spatially averaged between $4^{\circ} \mathrm{W}$ and $4^{\circ} \mathrm{E}$ and between $1^{\circ} \mathrm{S}$ and $1^{\circ} \mathrm{N}$. The $10-11$-day index is defined as the time-filtered surface zonal velocity, spatially averaged between $4^{\circ} \mathrm{W}$ and $4^{\circ} \mathrm{E}$ and between $3^{\circ} \mathrm{S}$ and $1^{\circ} \mathrm{S}$. Finally, the $30-45$-day index is defined as the timefiltered surface zonal velocity, spatially averaged between $4^{\circ} \mathrm{W}$ and $4^{\circ} \mathrm{E}$ and between $1^{\circ} \mathrm{S}$ and $1^{\circ} \mathrm{N}$. A summary of these different indices is given in Table 1. A wavelet analysis of the time series used to compute the different indices, prior to any time filtering, is shown in
Fig. 11. In the 15-20-day band, the mixed Rossbygravity wave index is generally more energetic during boreal summer (Fig. 11a), in agreement with 15-20-day meridional wind stress fluctuations, which also peak
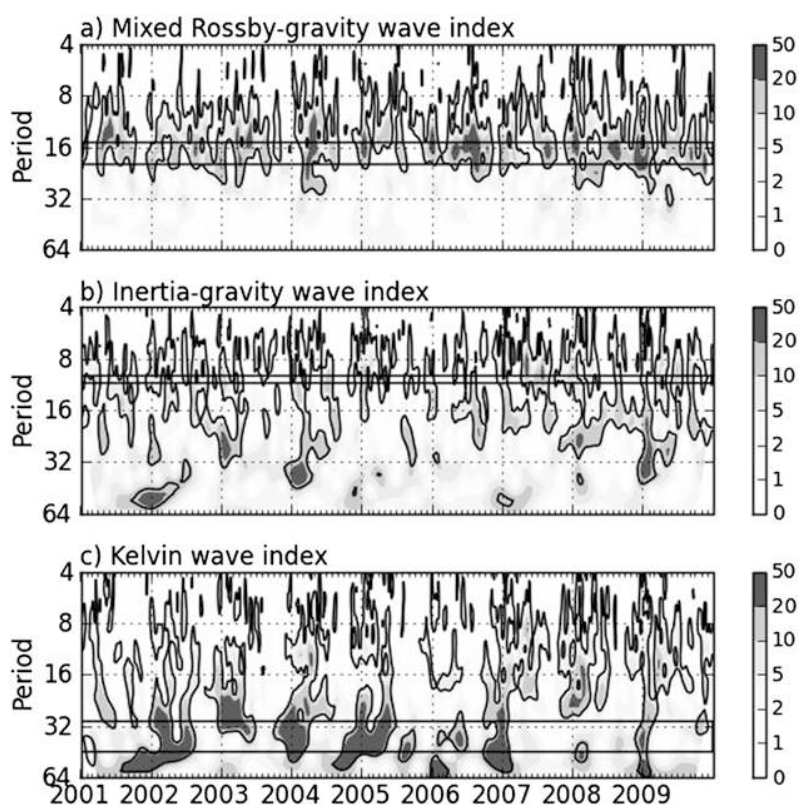

FIG. 11. Wavelet power spectrum of the three different indices used for the the regression analysis previous to bandpass time filtering: (a) meridional velocity averaged in the upper $10 \mathrm{~m}$ and between $4^{\circ} \mathrm{W}-4^{\circ} \mathrm{E}$ and $1^{\circ} \mathrm{S}-1^{\circ} \mathrm{N}$, (b) zonal velocity averaged in the upper $10 \mathrm{~m}$ between $4^{\circ} \mathrm{W}-4^{\circ} \mathrm{E}$ and $3^{\circ} \mathrm{S}-1^{\circ} \mathrm{S}$, and (c) zonal velocity averaged in the upper $10 \mathrm{~m}$ between $4^{\circ} \mathrm{W}-4^{\circ} \mathrm{E}$ and $1^{\circ} \mathrm{S}-1^{\circ} \mathrm{N}$. The power spectra are normalized by $\sigma^{2}$ the variance of the corresponding signals that is respectively $0.015,0.016$, and $0.013 \mathrm{~m}^{2} \mathrm{~s}^{-2}$. The black lines delimit the period bands over which the indices are then time filtered. The thick contour encloses regions of greater than $90 \%$ confidence for an $\mathrm{AR}(2)$ process. Vertical dashed lines indicate 1 Jan of each year. 
TABLE 1. Characteristic of the three indices used for the regression analysis.

\begin{tabular}{lclc}
\hline \hline Period band & Variable used to build the index & Averaged between & Dominant wave signal in this band \\
\hline $10-11$ days & Zonal velocity & $3^{\circ}-1^{\circ} \mathrm{S}$ and $4^{\circ} \mathrm{W}-4^{\circ} \mathrm{E}$ & Inertia-gravity \\
$15-20$ days & Meridional velocity & $1^{\circ} \mathrm{S}-1^{\circ} \mathrm{N}$ and $4^{\circ} \mathrm{W}-4^{\circ} \mathrm{E}$ & Rossby-gravity \\
$30-45$ days & Zonal velocity & $1^{\circ} \mathrm{S}-1^{\circ} \mathrm{N}$ and $4^{\circ} \mathrm{W}-4^{\circ} \mathrm{E}$ & Kelvin \\
\hline
\end{tabular}

during this season (Fig. 9f). But note that significant energy also occurs during the other seasons (Fig. 11a). In the 10-11-day band, the inertia-gravity wave index does not present a clear seasonal cycle (Fig. 11b). In the 3045-day band, the Kelvin wave index generally peaks at the beginning of the year (Fig. 11c). This is in agreement with the seasonal fluctuation of the zonal wind stress in this period band (Fig. 9e). The indices are normalized by their standard deviation. From integration of power spectral densities, we estimated that over the area between $4^{\circ} \mathrm{W}$ and $4^{\circ} \mathrm{E}$ and between $1^{\circ} \mathrm{S}$ and $1^{\circ} \mathrm{N}$, the three above frequency bands contain respectively $20 \%, 4 \%$, and $16 \%$ of the power of the mixed layer turbulent cooling contained at intraseasonal frequencies (i.e., periods between 2 and 50 days). Regression coefficients between these indices and various model fields are computed at each model grid point. Data were high-pass filtered with a cutoff period of 50 days before computation of the correlation coefficients. To help the discussion, we show in Fig. 12 the mean distribution of the different fields which have been regressed.

\section{a. Mixed Rossby-gravity waves (15-20-day band)}

The lagged regressions of the model outputs on the 1520-day index are shown from lag -4 (in days) to lag +4 in Fig. 13. We first investigate the nature and structure a) SST

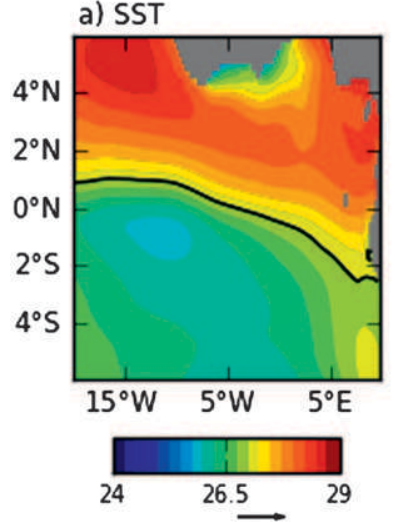

e) Tau $\quad 0.05 \mathrm{~N} / \mathrm{m} 2$

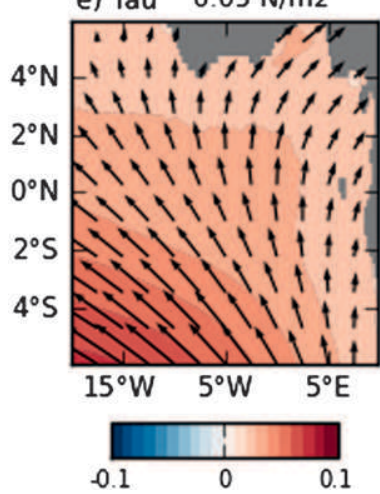

b) MLT-YAD

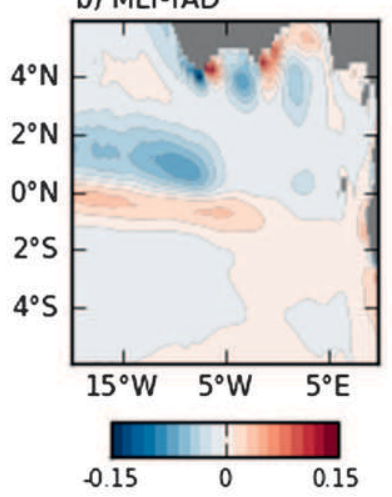

f) MLD / D20

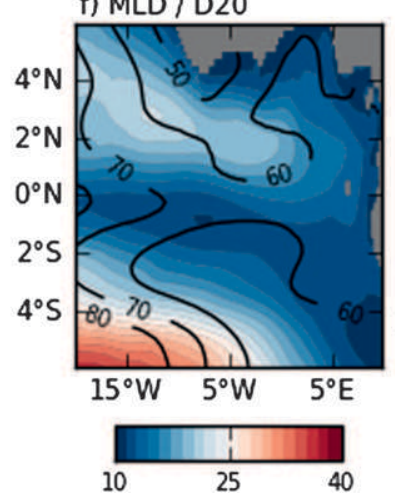

c) MLT-ZDF

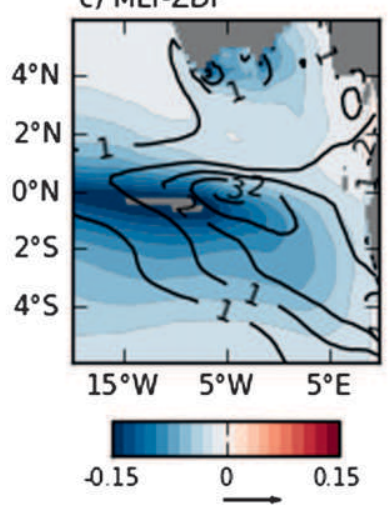

g) $U$

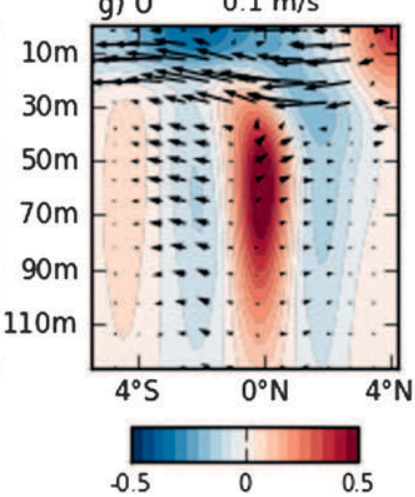

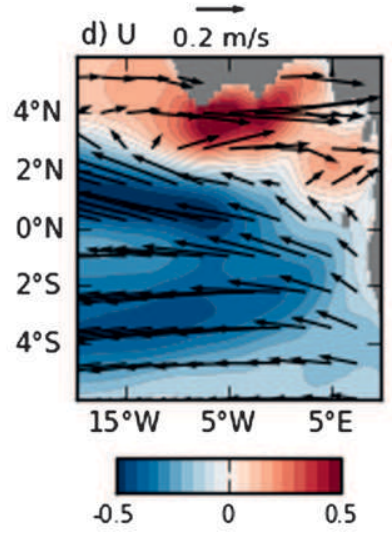

h) Shear

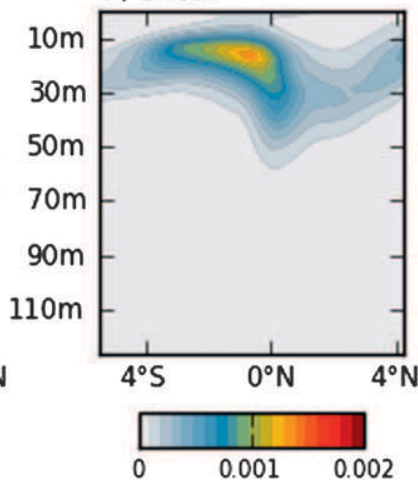

FIG. 12. Maps of the mean fields in the Gulf of Guinea from the simulation: (a) SST $\left({ }^{\circ} \mathrm{C}\right.$ ) and $27^{\circ} \mathrm{C}$ isotherm (solid line), (b) mixed layer temperature tendency due to meridional advection $\left({ }^{\circ} \mathrm{C}\right.$ day $\left.{ }^{-1}\right)$, (c) mixed layer temperature tendency due to vertical mixing $\left({ }^{\circ} \mathrm{C}\right.$ day $\left.{ }^{-1}\right)$ and vertical shear $10 \mathrm{~m}$ below the mixed layer depth in contours $\left(\mathrm{s}^{-2}\right)$, (d) zonal surface current (colors, $\mathrm{m} \mathrm{s}^{-1}$ ) and surface current vectors, (e) wind stress (colors, $\mathrm{N} \mathrm{m}^{-2}$ ) and wind stress vectors, and (f) the mixed layer depth $(\mathrm{m})$ and the depth of the isotherm $20^{\circ} \mathrm{C}$ in contours $(\mathrm{m})$. The two last figures are meridional sections at $0^{\circ}$ of $(\mathrm{g})$ zonal currents in colors $\left(\mathrm{m} \mathrm{s}^{-1}\right)$ together with meridional and vertical components of the current (vectors; for scaling purpose the vertical component has been multiplied by 3000$)$ and (h) vertical shear ( $\mathrm{s}^{-2}$ ). 

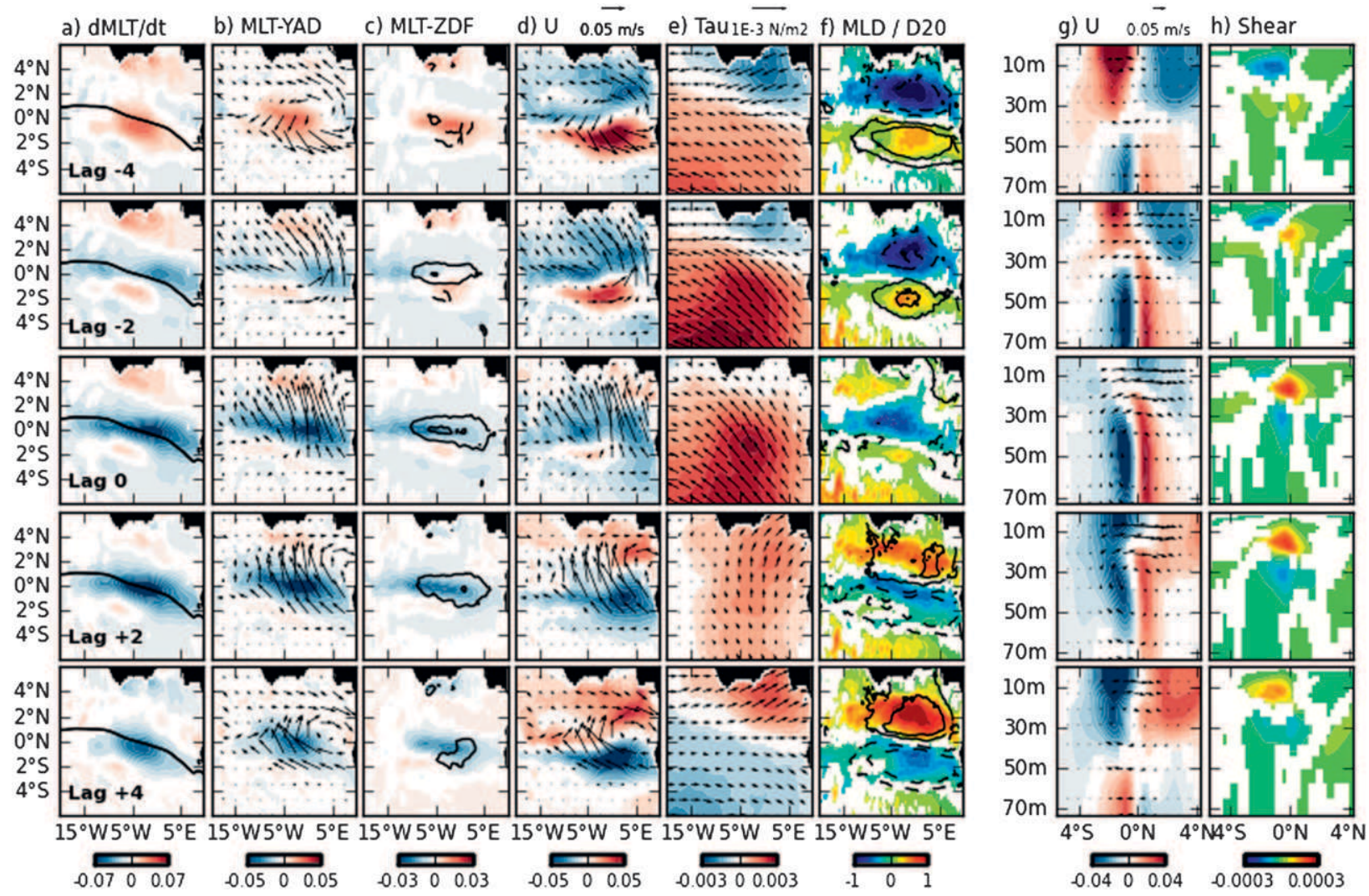

FIG. 13. Linear lagged regressions of different model outputs on an index of intraseasonal cooling. Lags range from -4 days to +4 days. To compute this index, the meridional surface velocity is averaged from $4^{\circ} \mathrm{W}$ to $4^{\circ} \mathrm{E}$ and from $1^{\circ} \mathrm{S}$ to $1^{\circ} \mathrm{N}$ and filtered with a bandpass Lanczos filter to retain the variability in the 15-20-day band. The different fields from (b) to (f) are the same as in Fig. 12 and (a) shows the regression of the mixed layer temperature tendency $\left({ }^{\circ} \mathrm{C} \mathrm{day}{ }^{-1}\right)$ together with the mean position of the $27^{\circ} \mathrm{C}$ isotherm. Data were low-pass filtered (50-day cutoff period) before the computation of the correlation coefficients. Correlation coefficients below the $90 \%$ confidence level are set to 0 . The confidence level is computed following the methodology described in Dewitte et al. (2011).

of the wave, which modulates the surface currents in the 15-20-day band. The anomalies of meridional surface current are maximum at the equator and as expected by construction they peak at lag 0 (Fig. 13d). The corresponding anomalies of zonal surface current (Fig. 13d) and $20^{\circ} \mathrm{C}$ isotherm depth (Fig. 13f, solid contours) are antisymmetric about the equator and are maximum near $2^{\circ} \mathrm{S}$ and $2^{\circ} \mathrm{N}$, with maximum amplitudes at lags -4 and +4 (i.e., in quadrature with the 15-20-day variability of meridional velocity variability). These space and time characteristics are in agreement with a westward-propagating mixed Rossby-gravity wave, as described for example in Weisberg et al. (1979) or Houghton and Colin (1987). The westward propagation can be seen from the successive maps of surface current anomalies from lag -4 to lag +4 . At lag -4 , the zonal surface current anomalies are westward north of the equator and eastward south of the equator. This structure moves westward and is progressively replaced by northward anomalies centered on the equator that are maximum at lag 0 . Then, out of phase zonal surface current anomalies of opposite sign to anomalies at lag -4 , start to form (lag +2$)$ near the African coast and travel westward $(\mathrm{lag}+4)$. The surface current anomalies are mainly confined between $15^{\circ} \mathrm{W}$ and the African coast (Fig. 13d), corresponding to a zonal wavelength of about $4000 \mathrm{~km}$. Considering a period of 16 days, this gives a westward phase speed of $2.89 \mathrm{~m} \mathrm{~s}^{-1}$ (see also Fig. 14b), an equivalent depth of $0.17 \mathrm{~m}$ and modal gravity wave speed of $1.31 \mathrm{~m} \mathrm{~s}^{-1}$, characteristic of a second baroclinic mode in the Tropical Atlantic (Du Penhoat and Tréguier 1985; Illig et al. 2004). So we suggest that 15-20-day oscillations in the Gulf of Guinea are windforced second baroclinic Rossby-gravity waves, in agreement with the conclusions of Houghton and Colin (1987). The peak of meridional velocities occurs at lag 0 between $5^{\circ} \mathrm{W}$ and $5^{\circ} \mathrm{E}$, i.e., at the end of the southeasterly wind burst which is maximum at the same longitudes (Figs. 13e and 14b). This suggests that the wave is forced by the wind. 

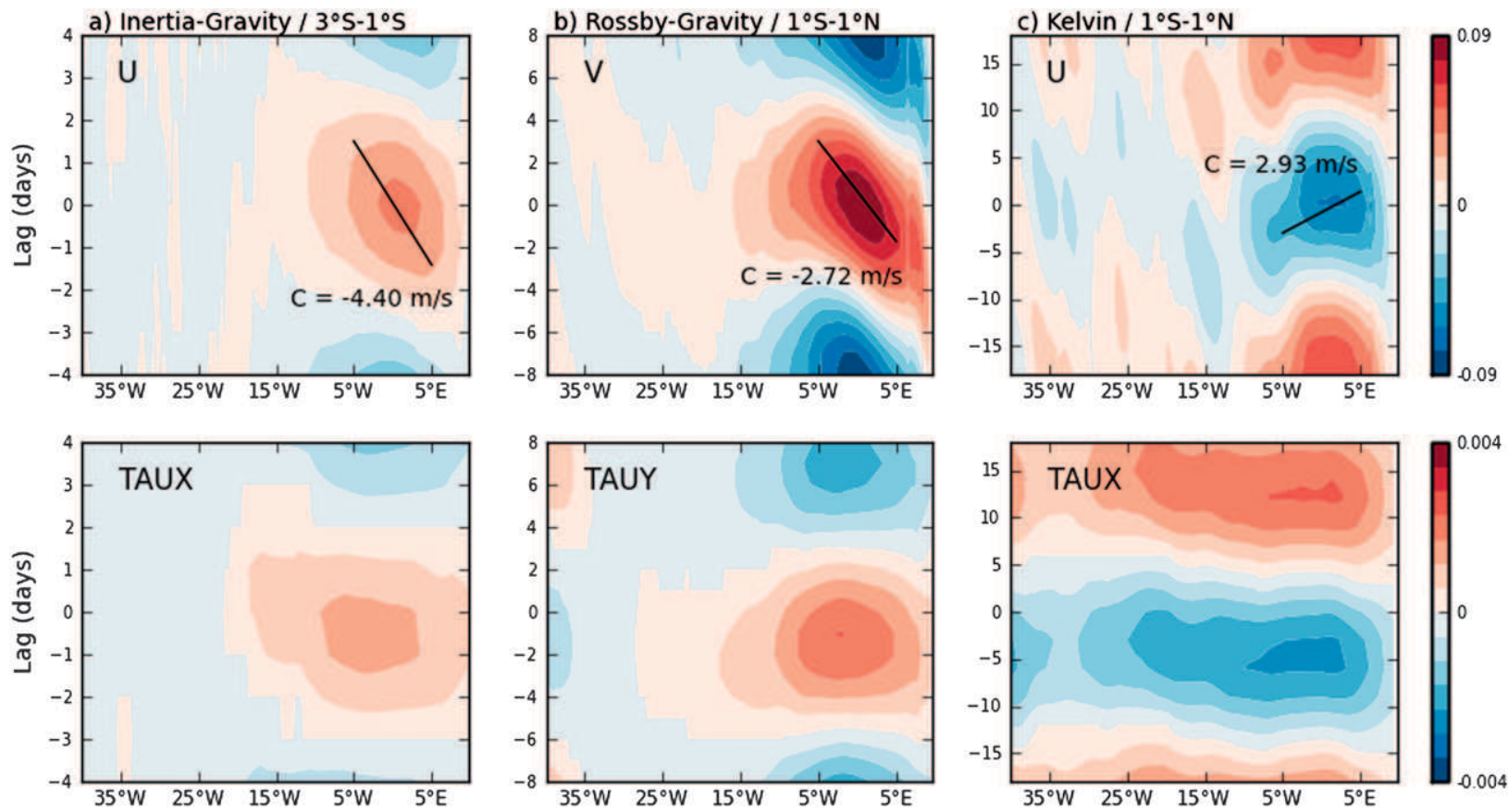

FIG. 14. Longitude-time diagrams of surface currents and wind stress regressed onto the three different intraseasonal indices defined in Table 1. Depending on the index, the variable and the meridional band used to average the regressed data are different: (a) inertia-gravity wave index: zonal velocity and zonal wind stress averaged between $3^{\circ}$ and $1^{\circ} \mathrm{S}$, (b) mixed Rossby-gravity wave index: meridional velocity and meridional wind stress averaged between $1^{\circ} \mathrm{S}$ and $1^{\circ} \mathrm{N}$, and (c) Kelvin wave index: zonal velocity and zonal wind stress averaged between $1^{\circ} \mathrm{S}$ and $1^{\circ} \mathrm{N}$. Units are $\mathrm{m} \mathrm{s}^{-1}$ and $\mathrm{N} \mathrm{m}^{-2}$.

From lag 0 to lag +4 , the anomalies of mixed layer temperature tendency indicate a strong cooling between $10^{\circ} \mathrm{W}$ and the African coast near the equator (Fig. 13a). The lag between the wind peak (Fig. 13e) and the mixed layer cooling (Fig. 13a) is of about 2 days, while the lag between the wind peak and the mixed layer temperature anomaly is roughly 6 days (not shown), in agreement with observations of de Coëtlogon et al. (2010).

The cooling results from two distinct mechanisms. The first mechanism is the northward migration of the SST front (Fig. 12a), in response to a positive anomaly in meridional velocities in the upper $20 \mathrm{~m}$ (Fig. 13d) which pushes the cold waters northward. Indeed, the term of mixed layer temperature tendency due to meridional advection (Fig. 13b) appears to largely control the mixed layer cooling (Fig. 13a). The anomaly of meridional velocity peaks at lags 0 and remains strong at lag +2 , as seen in the surface currents vectors (Fig. 13d), the latitude-time diagram at the equator (Fig. 14b) and in the meridional section at $0^{\circ}$ (Fig. $13 \mathrm{~g}$ ). The second mechanism is the enhanced turbulent cooling from lag 0 to lag +4 (Fig. 13c, colors), which is caused by increased vertical shear at the same lags between $2^{\circ} \mathrm{S}$ and the equator (Fig. 13h and contours in Fig. 13c). The comparison between color scales in Fig. 13b and 13c shows that the turbulent cooling anomalies are about half the size of the mixed layer temperature tendency due to meridional advection.

The vertical shear positive anomalies (Fig. 13c, solid contours) are predominantly due to westward anomaly of surface currents in the equatorial band (Fig. 13d and Fig. 13g). The zonal surface current anomalies responsible for increasing vertical shear above the EUC core appear to have two different origins depending on the phase of the wave. (i) At lag 0 , the westward zonal velocity anomaly is not zero at the equator, as expected for a theoretical mixed Rossby-gravity wave; this is likely due to the direct acceleration of the upper equatorial ocean in response to the zonal component of the strong south-east wind anomaly at lags -2 and 0 which forces the wave (Fig. 13e). (ii) At lags +2 and +4 , the westward zonal velocity anomalies above the EUC core (its upper part is located between $2^{\circ} \mathrm{S}$ and $0^{\circ} \mathrm{N}$, Fig. $13 \mathrm{~g}$ ) are on the contrary compatible with the time evolution and meridional structure of a mixed Rossby-gravity wave. The zonal surface current anomaly is then westward and maximum south of the equator, maintaining a strong vertical shear just south of the equator. This contrasts with the opposite phase of this 15-20-day variability (lag $-4)$, when the anomaly of surface current above the EUC is oriented eastward (Fig. 13d). Such anomaly then reduces the vertical shear, explaining why at this lag the 

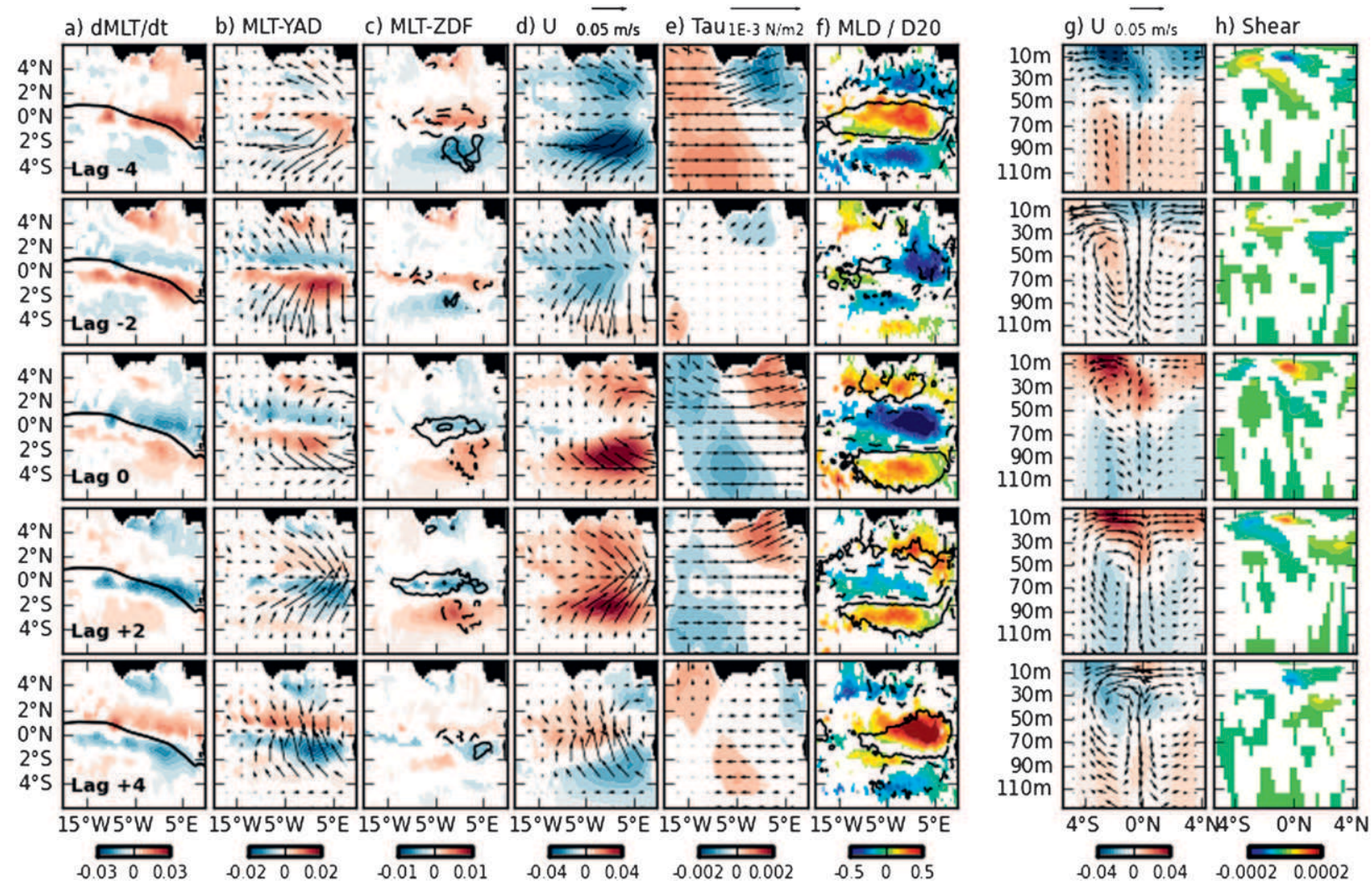

FIG. 15. Linear lagged regressions as in Fig. 13, but for the 10-11-day index. To compute this index, the zonal surface velocity is averaged between $4^{\circ} \mathrm{W}$ and $4^{\circ} \mathrm{E}$ and between $3^{\circ} \mathrm{S}$ and $1^{\circ} \mathrm{S}$ and filtered with a 10-11-day bandpass filter.

anomaly of mixed layer temperature tendency due to vertical mixing is positive (Fig. 13c). In subsurface, the antisymmetric structure of the zonal velocity anomalies between $50 \mathrm{~m}$ and $70 \mathrm{~m}$ (Fig. 13g) suggests that they are associated with meridional oscillations of the EUC, the EUC core being displaced north of its mean position from lags -4 to +2 and south from lag +4 (Fig. 13e). This meridional displacement of the EUC core may contribute to the modulation of the vertical shear and turbulent cooling, but we could not assess precisely its impact.

\section{b. Inertia-gravity waves (10-11-day band)}

Regressions are now carried out on the inertia-gravity waves index (10-11-day band). The time evolution of the spatial structure of the inertia-gravity wave is illustrated in Fig. 15d. Both zonal and meridional velocity anomalies are maximum off equator, close to $2^{\circ} \mathrm{S}$ and $2^{\circ} \mathrm{N}$. Zonal velocity anomalies are in phase on both sides of the equator while meridional velocity anomalies are out of phase about the equator. From lag -4 to lag +4 , the surface current anomalies rotate clockwise north of the equator and anticlockwise south of the equator. Such spatial structure is characteristic of a first meridional mode westward-propagating inertia-gravity wave (Matsuno 1966). From the regression analysis, we estimate a wavelength of about $4000 \mathrm{~km}$. Considering a period of 10.5 days, this leads to a westward phase speed of $4.4 \mathrm{~m} \mathrm{~s}^{-1}$ (Fig. 14a) and a modal gravity wave speed of $0.72 \mathrm{~m} \mathrm{~s}^{-1}$, which is typical of a fourth baroclinic mode in the Tropical Atlantic (Du Penhoat and Tréguier 1985). The fourth baroclinic mode is excited here because propagating inertia-gravity waves do not exist for the first three baroclinic modes at the 10-11 day period.

This inertia-gravity wave may be forced by the zonal component of large-scale wind perturbations (Figs. 15e and 14a). There are two arguments that support this hypothesis. First, the anomaly of the meridional component of the wind stress is almost null. Second, the anomalies of zonal surface currents are almost in phase with the anomalies of zonal wind stress (Figs. 15d,e and 14a).

The regression of the mixed layer temperature tendency shows that a peak of cooling occurs at the equator at lag 0 and between $2^{\circ} \mathrm{S}$ and the equator at lag +2 and +4 , from $10^{\circ} \mathrm{W}$ to the African coast (Fig. 15a). This cooling is due to both northward advection of surface cool waters (Fig. 15b) and enhanced turbulent heat flux (Fig. 15c). As in the 15-20-day band, the cooling induced 
by the 10-11-day modulations of the vertical mixing is about half the size of the cooling due to meridional advection. The anomalies of mixed layer temperature tendency due to meridional advection are particularly strong east of $0^{\circ} \mathrm{E}$ and between $2^{\circ} \mathrm{S}$ and the equator (Fig. 15b): the front of SST, located south of the equator in this region (Fig. 15a), is displaced alternatively southward (lag -2) and northward (e.g., lag +2 ) by the anomalous meridional surface currents.

The equatorial turbulent heat flux between lags 0 and 2 (Fig. 15c) is due at first order to enhanced vertical shear (Figs. 15c,h). Here the role of the zonal surface current (Figs. 15d,g) in controlling the vertical shear is not as clear as in the 15-20-day band. Indeed, the anomaly of surface zonal velocity at the equator is almost null at lag 0 and positive at lag +2 (Figs. 15d,g). But at these lags, the anomaly of vertical shear is strong (Fig. 15c,h). The eastward anomalies of subsurface zonal current (Fig. 15g) appear to be responsible for shear anomalies at lags 0 and +2 . These anomalies occur between 10 and $40 \mathrm{~m}$, mainly between $1^{\circ} \mathrm{S}$ and $0^{\circ}$, that is, at the upper limit of the mean EUC (see Fig. 12g). Note that a key ingredient for the vertical shear to be modulated by the variability of the EUC is the presence of a background westward zonal surface current. The inertia-gravity waves occur all along the year (Fig. 11b) and it should be for this reason that the impact of the waves on the turbulent cooling is stronger during periods with intensified SEC (Figs. 9a,b). This is achieved during summer, when the dominant westward zonal wind stress constrains the surface layer to flow westward at the equator.

The link between the eastward subsurface anomalies of zonal flow and peaks of vertical shear is also illustrated by the time-depth series of PIRATA and model variables at $0^{\circ}, 0^{\circ}$, for instance during April-August 2007 (Figs. 16c,e). During May, July, and August, both time series of PIRATA and model temperature present vertical fluctuations of the temperature at periods below 10 days. The vertical displacements of the isotherms are associated with large vertical velocities (Fig. 16d). These vertical velocities modulate the upper position of the EUC core, which results in a strong variability of the horizontal current between 10 and $30 \mathrm{~m}$. In agreement with the regression analysis, we remark that almost each time the EUC is at its uppermost position, a peak of vertical shear occurs (Fig. 16e).

The regression analysis suggests that the eastward anomalies of subsurface current at 10-11-day period are associated with vertical oscillations of the EUC core under the influence of the inertia-gravity waves. This is supported by the vertical dipole of zonal velocity anomalies along the vertical axis of the EUC at lag 0 (Fig. 15g): positive anomalies occur between 10 and $30 \mathrm{~m}$ at the

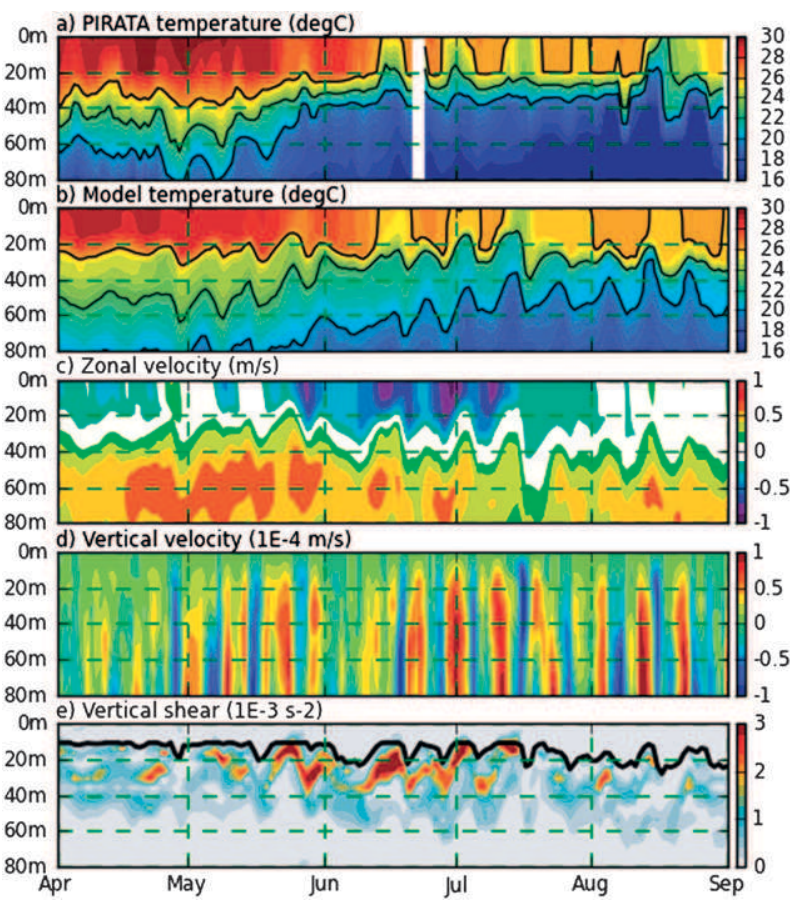

FIG. 16. Time-depth diagrams at $0^{\circ}, 0^{\circ}$ of (a) observed PIRATA temperature $\left({ }^{\circ} \mathrm{C}\right)$, (b) model temperature $\left({ }^{\circ} \mathrm{C}\right)$, (c) model zonal velocity $\left(\mathrm{m} \mathrm{s}^{-1}\right),(\mathrm{d})$ model vertical velocity $\left(10^{-4} \mathrm{~m} \mathrm{~s}^{-1}\right)$, and (e) vertical velocity shear $\left(10^{-3} \mathrm{~s}^{-2}\right)$. Black lines represent the $20^{\circ}, 23^{\circ}$, and $26^{\circ} \mathrm{C}$ isotherms in (a),(b) and the depth of the model mixed layer in (e). Data are shown from April to August 2007. The reason we choose this period is that the variability during summer 2006 is dominated by 15-20-day events (see Fig. 11b) and events at periods below 10 days are not as well highlighted as during 2007 .

upper limit of the EUC and negative anomalies occur between 70 and $110 \mathrm{~m}$ at the lower limit of the EUC (Fig. 12g). The divergence/convergence patterns of the meridional surface currents are associated with strong vertical velocities at the equator and off equator (between $4^{\circ}$ and $2^{\circ} \mathrm{S}$ and between $2^{\circ}$ and $4^{\circ} \mathrm{N}$ ), which form anomalous meridional cells of about $100-\mathrm{m}$ depth and $4^{\circ}$ latitudinal width in both hemispheres. At lags -4 and -2 , near surface meridional velocities are poleward (Figs. 15d,g), producing a divergence of the surface currents and upward vertical velocities (Fig. 15g). At lags +2 and +4 , the meridional surface velocities reverse to become equatorward and cause a near-surface convergence which forces downward vertical velocities and reduces the eastward anomaly of the subsurface zonal velocities (Fig. 15g).

The inertia-gravity waves also modulate significantly the mixed layer turbulent cooling between $4^{\circ} \mathrm{S}$ and $1^{\circ} \mathrm{S}$. This occurs at lags $-4,-2$, and +2 (Fig. 15c), when off equatorial zonal velocity anomalies create anomalous vertical shear (Fig. 15c,d). The difference of amplitude of the velocity anomalies north and south of the equator 

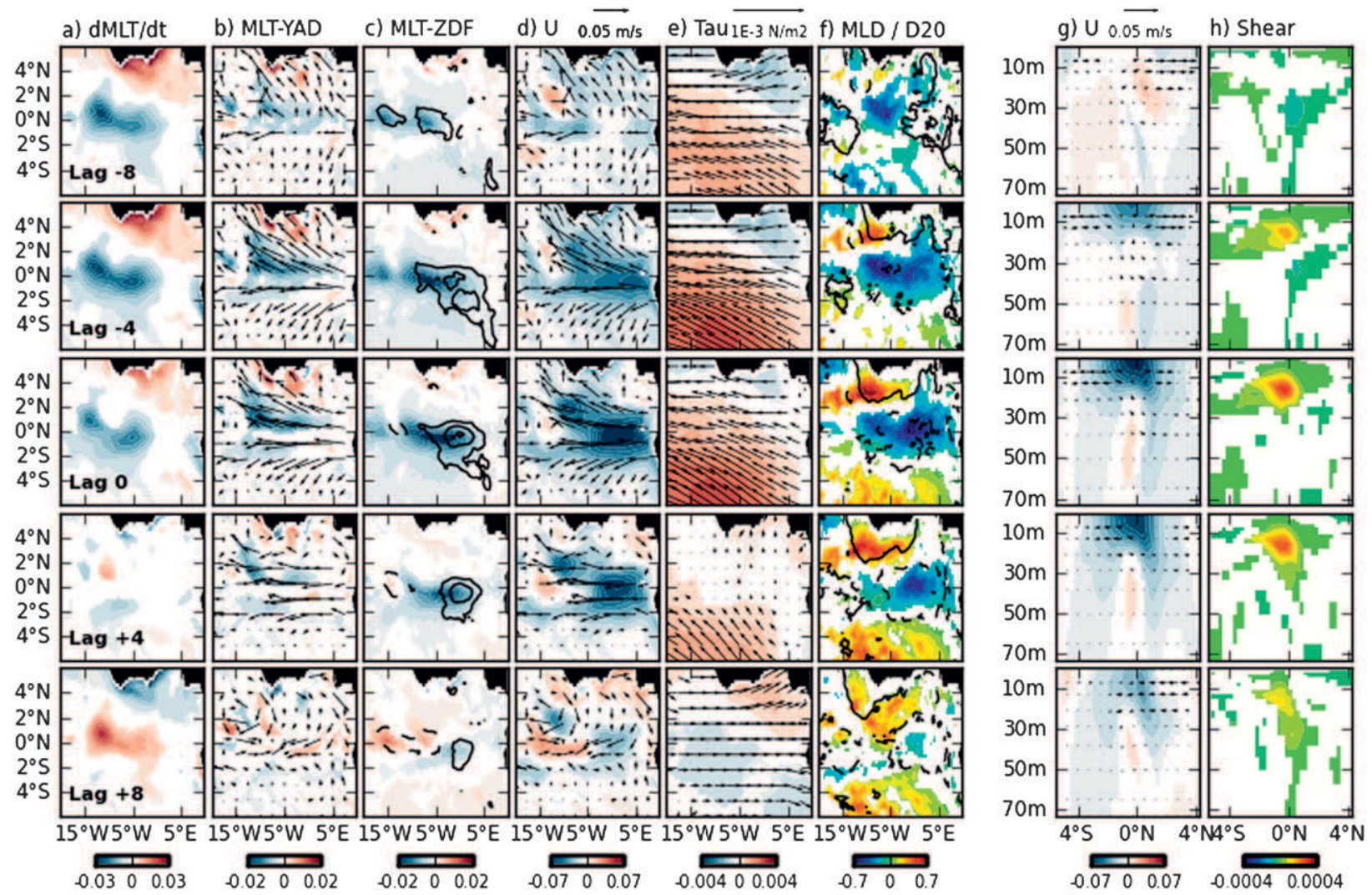

FIG. 17. Linear lagged regressions as in Fig. 13, but for the 30-45-day index. To compute this index, the zonal surface velocity is averaged between $4^{\circ} \mathrm{W}$ and $4^{\circ} \mathrm{E}$ and between $1^{\circ} \mathrm{S}$ and $1^{\circ} \mathrm{N}$ and filtered with a 30-45-day bandpass filter. At the difference of Fig. 13 and 15 , lags range from -8 days to +8 days.

(Fig. 15d) mostly explains why significant turbulent cooling is induced between $4^{\circ} \mathrm{S}$ and $1^{\circ} \mathrm{S}$ and why the velocity anomalies north of the equator have almost no impact on the turbulent cooling. The north-south differences of background shear highlighted in this region in Jouanno et al. (2011a), and the $0.5^{\circ}$ southward shift of the upper part of the EUC (Fig. 12g) may additionally contribute to this asymmetry. Note that this off equatorial cooling caused by an inertia-gravity wave is in agreement with high power spectra of mixed layer turbulent cooling, which is shown off equator at periods between 8 and 14 days (Fig. 7a). It was verified that the north-south difference of zonal velocity anomalies is not an artifact due to the construction of the index with zonal velocities south of the equator (see Table 1). Indeed, the regression analysis carried out with an index constructed with zonal velocities averaged between $3^{\circ}$ and $1^{\circ} \mathrm{S}$ and between $1^{\circ}$ and $3^{\circ} \mathrm{N}$ leads to the same results.

\section{c. Kelvin waves (30-45-day band)}

The regression on the 30-45-day index reveals different regimes of variability east and west of $10^{\circ} \mathrm{W}$. East of $10^{\circ} \mathrm{W}$, the surface currents anomalies between lag -8 and lag +8 show equatorially trapped westward surface velocity anomaly (Fig. 17d) and negative anomaly of the depth of isotherm $20^{\circ} \mathrm{C}$ (Fig. 17f, solid contours) propagating eastward from $10^{\circ} \mathrm{W}$ to the African coast, in agreement with the spatial structure of an equatorial Kelvin wave. This eastward propagation is also shown in longitude-time diagram of the zonal velocity at the equator (Fig. 14c). We estimate a phase speed of $2.9 \mathrm{~m} . \mathrm{s}^{-1}$, which corresponds to a propagation of about $2000 \mathrm{~km}$ in 6 days. This is consistent with the first baroclinic mode Kelvin waves in the equatorial Atlantic (Du Penhoat and Tréguier 1985; Illig et al. 2004). In this band of frequency, anomalous westward winds occur in a large area over the Tropical Atlantic (Fig. 14c), suggesting that these Kelvin waves could be remotely forced. The eastward velocity anomaly visible at lag +8 along the northern coast of the Gulf of Guinea illustrates that this signal propagates poleward as a coastally trapped Kelvin wave.

West of $10^{\circ} \mathrm{W}$, the anomalies of surface currents and depth of isotherm $20^{\circ} \mathrm{C}$ (Fig. 17d and Fig. 17f, solid contours) are maximum between the equator and $3^{\circ} \mathrm{N}$, propagate slowly westward and have smaller zonal 
wavelengths (see also Fig. 14c). Such characteristics resemble that of TIWs. The fact that the regression analysis extracts both signals east and west of $10^{\circ} \mathrm{W}$ suggests a phase relationship between both signals. We will however not analyze further this aspect since our main focus is the Gulf of Guinea, and since TIWs mostly occur out of this region.

The westward surface current anomalies induced by the Kelvin wave (Fig. 17d), increase the vertical shear (Fig. 17c and 17h) and consequently the mixed layer turbulent cooling east of $10^{\circ} \mathrm{W}$ (Fig. 17c). The turbulent cooling contributes significantly to the mixed layer temperature tendency (Fig. 17a), in this case comparable to the meridional advection. On the northern and southern edges of the maximum zonal velocity anomalies, meridional velocity anomalies are nonzero. This explains the mixed layer cooling caused by meridional advection, which occurs north of the equator between $10^{\circ} \mathrm{W}$ and $0^{\circ}$ at lags -4 and 0 (Fig. 17b). Because of the east-west gradient of SST (Fig. 12a), mixed layer warming is caused by zonal advection between lag -4 and +4 (not shown) and largely counterbalances the cooling due to meridional advection and turbulent mixing, resulting in only weak cooling anomalies east of $0^{\circ} \mathrm{E}$ (Fig. 17a).

\section{Discussion and summary}

This work describes the main dynamical regimes of intraseasonal variability in the Gulf of Guinea and investigates the mechanisms whereby they contribute to SST intraseasonal variability. A regional model of the Tropical Atlantic forced with ERA-Interim reanalysis is analyzed during the period 2001 to 2009. Comparisons with PIRATA and satellite observations show that the model adequately represents the intraseasonal variability of the SST. Although the contribution of the TIWs to mixed layer cooling has been investigated in previous studies in other oceans (Menkes et al. 2006; Lien et al. 2008; Moum et al. 2009), the present study is to our knowledge the first to investigate in detail the turbulent cooling due to the different regimes of intraseasonal variability other than TIWs.

The most energetic intraseasonal signal found in the Gulf of Guinea is that of 15-20-day mixed Rossbygravity waves. A regression analysis of model outputs allowed for isolating the spatial structure of these waves. We found a westward propagation and an horizontal wavelength of about $4000 \mathrm{~km}$, in agreement with Hallock (1979) who showed with a $2 \frac{1}{2}$ model that the dominant response to a meridional wind forcing is a westward propagating mixed Rossby-gravity wave of about 17-day period. Comparing the reference simulation with a simulation forced without intraseasonal winds, we have shown that the production of energetic TIWs is limited to the central basin and that these TIWs do not radiate energetic waves toward the Gulf of Guinea. This confirms that the mixed Rossby-gravity waves in the Gulf of Guinea are wind driven. From a linear model, Han et al. (2008) have shown that mixed Rossby-gravity waves in the equatorial Atlantic can be excited in the central or western basin. We found that the correlation between the mixed Rossby-gravity wave index and the wind stress is maximum in the Gulf of Guinea (Figs. 13e and 14a). This suggests a contribution of the local wind but from our analysis we cannot determine the respective contributions of local and remote wind forcings to these mixed Rossby-gravity waves. This question would require further analysis.

In the Gulf of Guinea, energetic fluctuations of the surface currents have also been identified at periods lower than 11 days and associated with wind-forced inertia-gravity waves. Bunge et al. (2007) observed at $0^{\circ}$, $23^{\circ} \mathrm{W}$ fluctuations of both currents and near surface temperature with periodicity of 5-7 days. They suggest that these near-surface temperature fluctuations are linked to vertical movements of the thermocline, in agreement with our model. We show that these fluctuations are mainly due to equatorial convergence/ divergence of the surface flow associated with inertiagravity waves.

At periods between 30 and 45 days, different dynamical regimes are found east and west of $10^{\circ} \mathrm{W}$, in agreement with observations of Athié and Marin (2008). West of $10^{\circ} \mathrm{W}$, the $30-45$-day signal shows TIWs while east of $10^{\circ} \mathrm{W}$, the signal is dominated by eastward propagating Kelvin waves. The occurrence of Kelvin waves is in agreement with Han et al. (2008) who found that wind-forced equatorial Kelvin waves can, at times (e.g., spring 2002), dominate the SST and the sea level height variability at 10-40-day time scales in the entire Equatorial Atlantic. Bunge et al. (2007) observed SST anomalies east of $10^{\circ} \mathrm{W}$ centered on the equator with the same periodicity as the TIWs in the west, but with larger zonal scale and no evident propagation. They were unable to diagnose the cause of this variability and could not establish the link with TIWs. Our results suggest that the events they observed east of $10^{\circ} \mathrm{W}$ were Kelvin waves. Athié and Marin (2008) also found in the TIW period range a nonpropagative signal east of $10^{\circ} \mathrm{W}$ and centered on the equator. It is worth mentioning that the methods they used could miss fast eastward propagation. Interestingly the regression analysis suggests that the TIWs and the Kelvin waves are phase locked. The variability of the Kelvin wave index is maximum during winter (Fig. 9c). So this suggests that such phasing may 
only be valid during winter which is a secondary season for TIWs production (Jochum et al. 2004; Han et al. 2008). But these aspects are out of the scope of the paper and would require further investigation.

The mechanisms whereby these waves impact the mixed layer temperature were estimated through online computation of the different terms of the mixed layer heat budget. The contribution of meridional advection to the mixed layer heat budget generally dominate the intraseasonal variations of the mixed layer temperature in the Gulf of Guinea due to the position, close to the equator, of the northern front of the mean seasonal cold tongue in the Gulf of Guinea. But it is found that the different waves induce significant net turbulent cooling of the mixed layer through modulation of the vertical shear. During May-August, which is the period of 1) formation of the seasonal cold tongue (e.g., Jouanno et al. 2011a) and 2) strong intraseasonal variability of the turbulent cooling (Fig. 9b), the mean turbulent heat flux at $0^{\circ}$ at the base of the mixed layer reaches values of up to $60 \mathrm{~W} \mathrm{~m}^{-2}$ near the equator, in agreement with recent observations by Hummels et al. (2013). The modulation of the turbulent heat fluxes by the different regimes of intraseasonal variability is significant compared to this mean value: standard deviations reach $25 \mathrm{~W} \mathrm{~m}^{-2}$ in the 13-20-day band, $30 \mathrm{~W} \mathrm{~m}^{-2}$ in the 2-11-day band, and $20 \mathrm{~W} \mathrm{~m}^{-2}$ in the 25-40-day band. The strongest fluctuations of the turbulent cooling occur above the EUC, suggesting that its presence is a key ingredient for equatorial waves to modulate the vertical mixing. This is explained by the nonlinearity of the vertical mixing process. The spatial structure of the mixed Rossbygravity waves leads to zonal surface flow anomalies at and south of the equator which increase the vertical shear above the EUC. The westward zonal surface current anomalies are reinforced by the zonal component of the southeasterlies wind bursts, which force the mixed Rossby-gravity waves. In the 10-11-day inertia-gravity band, we demonstrate that at the equator, the waves modulate the heat flux at the mixed layer base mainly through vertical displacement of the EUC core in response to equatorial divergence and convergence. We verified that this mechanism holds for other frequency bands characteristic of inertia-gravity waves (8-10-day and 6-8-day; not shown), suggesting that inertia-gravity waves of the first meridional mode (i.e., with meridional velocity antisymmetric about the equator) are preferentially forced in the region. This also explains why at these frequencies, there is a peak of variability of the turbulent heat flux at the equator whereas the maximum variability of the surface current occurs off equator. This cooling induced by inertia-gravity waves is also in agreement with Bunge et al. (2007) who proposed that the temperature fluctuations in the 5-10-day band could contribute to the heat exchange at the mixed layer base. The inertia-gravity waves are also shown to induce significant turbulent cooling between $4^{\circ} \mathrm{S}$ and $2^{\circ} \mathrm{S}$, when the wave induces westward anomalies of surface velocity at these latitudes. At periods between 30 and 45 days, westward anomalies of surface equatorial current, associated with the eastward propagation of equatorial Kelvin waves are shown to enhance the turbulent mixing above the EUC core. It has been verified that neither the intraseasonal variability of the thermocline depth nor the variability of the mixed layer depth can explain the modulation of the turbulent cooling (see Figs. 13, 15, and 17). In addition, the contribution of the vertical advection to the mixed layer heat budget is small compared to the contribution of the turbulent heat fluxes.

Although energetic waves in the different period bands occur all along the year, the impact of the different waves on the turbulent heat flux is found to be strongest during periods of seasonal cooling and in particular during boreal summer, when the SEC is strong. We suggest that this is mainly due to the dependence of the vertical mixing process on the square value of the vertical shear.

In agreement with Athié et al. (2009), our results suggest that the intraseasonal variability in the Gulf of Guinea is wind forced. So an important issue is to understand the nature and the origin of the wind fluctuations. Marin et al. (2009) and de Coëtlogon et al. (2010) associated the 15-day wind bursts in the Gulf of Guinea to the variability of the St Helena anticyclone. On the one hand, de Coëtlogon et al. (2010) proposed that the biweekly periodicity could be supported by coupled interactions between SST and surface wind anomalies in the equatorial band. On the other hand, Janicot et al. (2011) identified two atmospheric modes of surface wind in West Africa with a mean periodicity of 15 days. Both modes present important amplitude in the Gulf of Guinea and are associated with air-land processes over Africa. We could not identify which of the two modes force the biweekly oceanic variability. The response and sensitivity of the ocean to different atmospheric biweekly modes would require further investigations. To our knowledge, the origin and the mechanisms of wind variability at the other frequencies highlighted in this study (10-11 and 30-45 day) are not documented.

It is striking that the higher impact of the waves on the mixed layer turbulent cooling is from May to August, during the formation of the seasonal cold tongue. Since the numerical results suggest that these oceanic waves are mainly forced by intraseasonal winds, it confirms and extends the results of Athié et al. (2009) who argued that the energy contained by the wind at high frequencies 
may have important consequences on the surface mixed layer heat budget. Although we could not quantify the overall impact of the waves on the seasonal heat budget, the results point out that an accurate high-frequency variability in the wind products might be crucial to improve the simulation of the seasonal cycle of the equatorial Atlantic cold tongue. Finally, this study also suggests that the interannual modulation of the intraseasonal waves could contribute to the interannual variability of the seasonal cold tongue. This point has not been investigated and deserves further attention.

Acknowledgments. This study was supported by the Institut de Recherche pour le Développement and is part of the ANVISAT project funded by the Groupe Mission Mercator Coriolis. TMI data were produced by Remote Sensing Systems and sponsored by the NASA Earth Science REASon DISCOVER Project. TMI data are available at http://www.remss.com. We acknowledge the PIRATA Project and TAO Project Office at NOAA/ PMEL for providing open access to PIRATA data. We acknowledge the provision of supercomputing facilities by the CICESE. The regional configuration was set up in cooperation with the DRAKKAR project (http:// www.drakkar-ocean.eu/). We are grateful to two anonymous reviewers for their comments and suggestions.

\section{REFERENCES}

Athié, G., and F. Marin, 2008: Cross-equatorial structure and temporal modulation of intraseasonal variability at the surface of the tropical Atlantic Ocean. J. Geophys. Res., 113, C08020, doi:10.1029/2007JC004332.

- — - A.-M. Tréguier, B. Bourles, and C. Guiavarc'h, 2009: Sensitivity of near-surface tropical instability waves to submonthly wind forcing in the tropical Atlantic. Ocean Modell., 30, 241-255.

Barnier, B., and Coauthors, 2006: Impact of partial steps and momentum advection schemes in a global ocean circulation model at eddy-permitting resolution. Ocean Dyn., 56 (5-6), 543-567.

Bentamy, A., K. B. Katsaros, W. M. Drennan, and E. B. Forde, 2002: Daily surface wind fields produced by merged satellite data. Gas Transfer at Water Surfaces, Geophys. Monogr., Vol. 127, Amer. Geophys. Union, 343-349.

Blanke, B., and P. Delecluse, 1993: Variability of the tropical Atlantic Ocean simulated by a general circulation model with two different mixed layer physics. J. Phys. Oceanogr., 23, 1363-1388.

Bourlès, B., and Coauthors, 2008: The PIRATA program: History, accomplishments, and future directions. Bull. Amer. Meteor. Soc., 89, 1111-1125.

Bunge, L., C. Provost, and A. Kartavtseff, 2007: Variability in horizontal current velocities in the central and eastern equatorial Atlantic in 2002. J. Geophys. Res., 112, C02014, doi:10.1029/2006JC003704.
Caniaux, G., H. Giordani, J. L. Redelsperger, F. Guichard, E. Key, and M. Wade, 2011: Coupling between the Atlantic cold tongue and the West African monsoon in boreal spring and summer. J. Geophys. Res., 116, C04003, doi:10.1029/ 2010JC006570.

Carton, J. A., and Z. Zhou, 1997: Annual cycle of sea surface temperature in the tropical Atlantic Ocean. J. Geophys. Res., 102 (C13), 27 813-27 824.

de Coëtlogon, S. J., G. Madec, A. S. Fischer, A. Lazar, and D. Iudicone, 2010: Intraseasonal variability of the oceanatmosphere coupling in the Gulf of Guinea during boreal spring and summer. J. Geophys. Res., 109, C120031, doi:10.1029/ 2004JC002378.

Dee, D. P., and Coauthors, 2011: The ERA-Interim reanalysis: Configuration and performance of the data assimilation system. Quart. J. Roy. Meteor. Soc., 137, 553-597, doi:10.1002/ qj. 828 .

Dewitte, B., S. Illig, L. Renault, K. Goubanova, K. Takahashi, D. Gushchina, K. Mosquera, and S. Purca, 2011: Modes of covariability between sea surface temperature and wind stress intraseasonal anomalies along the coast of Peru from satellite observations (2000-2008). J. Geophys. Res., 116, C04028, doi:10.1029/2010JC006495.

Du Penhoat, Y., and A. M. Tréguier, 1985: The seasonal linear response of the Atlantic Ocean. J. Phys. Oceanogr., 15, 316-329.

Hallock, Z., 1979: On wind-exited, equatorially trapped waves in the presence of mean currents. Deep-Sea Res., 26 (GATE Suppl. II), 262-284.

Han, W., P. J. Webster, J.-L. Lin, W. T. Liu, R. Fu, D. Yuan, and A. Hu, 2008: Dynamics of intraseasonal sea level and thermocline variability in the equatorial Atlantic during 2002-03. J. Phys. Oceanogr., 38, 945-966.

Houghton, R. W., and C. Colin, 1987: Wind-driven meridional heat flux in the Gulf of Guinea. J. Geophys. Res., 92 (C10), $10777-$ 10786.

Hummels, R., M. Dengler, and B. Bourlès, 2013: Seasonal and regional variability of upper ocean diapycnal heat flux in the Atlantic Cold Tongue. Prog. Oceanogr., doi:10.1016/j.pocean. 2012.11.001, in press.

Illig, S., B. Dewitte, N. Ayoub, Y. du Penhoat, G. Reverdin, P. De Mey, F. Bonjean, and G. S. Lagerloef, 2004: Interannual long equatorial waves in the tropical Atlantic from a highresolution ocean general circulation model experiment in 1981 - 2000. J. Geophys. Res., 109, C02022, doi:10.1029/ 2003JC001771.

Janicot, S., and Coauthors, 2011: Intraseasonal variability of the West African monsoon. Atmos. Sci. Lett., 12, 58-66.

Jochum, M., P. Malanotte-Rizzoli, and A. Busalacchi, 2004: Tropical instability waves in the Atlantic Ocean. Ocean Modell., 7, 145163.

Jouanno, J., F. Marin, Y. Du Penhoat, J.-M. Molines, and J. Sheinbaum, 2011a: Seasonal modes of surface cooling in the Gulf of Guinea. J. Phys. Oceanogr., 41, 1408-1416.

,$- \ldots$, J. Sheinbaum, and J.-M. Molines, 2011b: Seasonal heat balance in the upper $100 \mathrm{~m}$ of the equatorial Atlantic Ocean. J. Geophys. Res., 116, C09003, doi:10.1029/ 2010JC006912.

Krishnamurti, T. N., and T. Krishnamurti, 1980: Surface meteorology over the GATE A-scale. Deep-Sea Res., 26 (GATE Suppl. II), 26-61.

Kummerow, C., W. Barnes, T. Kozu, J. Shiue, and J. Simpson, 1998: The Tropical Rainfall Measuring Mission (TRMM) sensor package. J. Atmos. Oceanic Technol., 14, 809-817. 
Large, W., and S. Yeager, 2004: Diurnal to decadal global forcing for ocean sea ice models: The datasets and flux climatologies. National Center for Atmospheric Research Rep. NCAR/ TN-460+STR, 105 pp.

Lien, R.-C., E. A. D'Asaro, and C. E. Menkes, 2008: Modulation of equatorial turbulence by tropical instability waves. Geophys. Res. Lett., 35, L24607, doi:10.1029/2008GL035860.

Madec, G., 2008: "NEMO ocean engine." Institut Pierre-Simon Laplace Note du pôle de modélisation 27, 367 pp.

Marin, F., G. Caniaux, B. Bourlès, H. Giordanni, Y. Gouriou, and E. Key, 2009: Why were sea surface temperatures so different in the eastern equatorial Atlantic in June 2005 and 2006? J. Phys. Oceanogr., 39, 1416-1431.

Matsuno, T., 1966: Quasigesotrophic motions in the equatorial area. J. Meteor. Soc. Japan, 44, 25-42.

McPhaden, M. J., 1990: Comment on "Rossby-gravity waves in the central equatorial Pacific Ocean during the NORPAX Hawaii-to-Tahiti shuttle experiment" by S. M. Chiswell and R. Lukas. J. Geophys. Res., 95 (C1), 805-806.

Menkes, C. E., J. Vialard, S. C. Kennan, J.-P. Boulanger, and G. Madec, 2006: A modeling study of the impact of tropical instability waves on the heat budget of the eastern equatorial Pacific. J. Phys. Oceanogr., 36, 847-865.

Moum, J. N., R.-C. Lien, A. Perlin, J. D. Nash, M. C. Gregg, and P. J. Wiles, 2009: Sea surface cooling at the Equator by subsurface mixing in tropical instability waves. Nat. Geosci., 2, 761-765.

Okumura, Y. M., and S.-P. Xie, 2004: Interaction of the Atlantic equatorial cold tongue and the African monsoon. J. Climate, 17, 3589-3602.

Perez, R. C., R. Lumpkin, W. E. Johns, G. R. Foltz, and V. Hormann, 2012: Interannual variations of Atlantic tropical instability waves. J. Geophys. Res., 117, C03011, doi:10.1029/2011JC007584.
Peter, A.-C., M. Le Hénaff, Y. Du Penhoat, C. E. Menkes, F. Marin, J. Vialard, G. Caniaux, and A. Lazar, 2006: A model study of the seasonal mixed layer heat budget in the equatorial Atlantic. J. Geophys. Res., 111, C06014, doi:10.1029/2005JC003157.

Philander, S. G. H., 1978: Forced oceanic waves. Rev. Geophys. Space Phys., 16, 15-46.

Picaut, J., 1983: Propagation of the seasonal upwelling in the eastern Equatorial Atlantic. J. Phys. Oceanogr., 13, 18-37.

_ 1984: On the dynamics of thermal variations in the Gulf of Guinea. Oceanogr. Trop., 19, 127-153.

Praveen Kumar, B., J. Vialard, M. Lengaigne, V. S. N. Murty, M. J. McPhaden, M. Cronin, F. Pinsard, and K. Gopala Reddy, 2013: TropFlux wind stresses over the tropical oceans: Evaluation and comparison with other products, Climate Dyn., doi:10.1007/ s00382-012-1455-4, in press.

von Schuckmann, K., P. Brandt, and C. Eden, 2008: Generation of tropical instability waves in the Atlantic Ocean. J. Geophys. Res., 113, C08034, doi:10.1029/2007JC004712.

Wade, M., G. Caniaux, and Y. du Penhoat, 2011a: Variability of the mixed layer heat budget in the eastern equatorial Atlantic during 2005-2007 as inferred using Argo floats. J. Geophys. Res., 116, C08006, doi:10.1029/2010JC006683.

$-, \ldots,-$, M. Dengler, H. Giordani, and R. Hummels, 2011b: A one-dimensional modeling study of the diurnal cycle in the equatorial Atlantic at the PIRATA buoys during the EGEE-3 campaign. Ocean Dyn., 61, 1-20, doi:10.1007/s10236-010-0337-8.

Weisberg, R. H., A. Horigan, and C. Colin, 1979: Equatorially trapped Rossby-gravity wave propagation in the Gulf of Guinea. J. Mar. Res., 37, 67-86.

Yu, W., W. Han, E. D. Maloney, D. Gochis, and S.-P. Xie, 2011: Observations of eastward propagation of atmospheric intraseasonal oscillations from the Pacific to the Atlantic. J. Geophys. Res., 116, D02101, doi:10.1029/2010JD014336. 